NUREG/CR-0330

PNL-3232

Vol. 2

\title{
Ex-Reactor Determination of Thermal Gap Conductance Between Uranium Dioxide and Zircaloy-4
}

\section{Stage II: High Gas Pressure}

Prepared by J. Garnier, S. Begej

Pacific Northwest Laboratory

Operated by

Battelle Memorial Institute

Prepared for

U.S. Nuclear Regulatory

Commission 


\section{NOTICE}

This report was prepared as an account of work sponsored by an agency of the United States Government. Neither the United States Government nor any agency thereof, or any of their employees, makes any warranty, expressed or implied, or assumes any legal liability or responsibility for any third party's use, or the results of such use, of any information, apparatus product or process disclosed in this report, or represents that its use by such third party would not infringe privately owned rights.

Available from

GPO Sales Program

Division of Technical Information and Document Control

U. S. Nuclear Regulatory Commission Washington, D. C. 20555

Printed copy price: $\$ 3.75$

and

National Technical Information Service

Springfield, Virginia 22161 


\section{Ex-Reactor Determination of Thermal Gap Conductance Between Uranium Dioxide and Zircaloy-4}

Stage II: High Gas Pressure

Manuscript Completed: May 1980

Date Published: July 1980

Prepared by

J. Garnier, S. Begej

Pacific Northwest Laboratory

P.O. Box 999

Richland, WA 99352

Prepared for

Division of Reactor Safety Research

Office of Nuclear Regulatory Research

U.S. Nuclear Regulatory Commission

Washington, D.C. 20555

NRC FIN No. B2043 



\section{SUMMARY}

An ex-reactor study of the thermal gap conductance between Uranium Dioxide $\left(\mathrm{UO}_{2}\right)$ and Zircaloy-4 ( $\left.\mathrm{Zr} 4\right)$ was performed under varying conditions of gas pressure (0.1 to $7 \mathrm{MPa}$ ); temperature (283 to $673 \mathrm{~K}$ ); gas composition (He (100); $\operatorname{Ar}(100)$; He:Ar (51.79:48.21); and He:Xe (89.4:10.6)); and, average mean-plane separation distance $D_{m p}=5.9 \mu m$ (1ight contact); and, $\left.D_{m p}=23.1 \mu \mathrm{m}\right)$.

In this report a description of the high pressure autoclave, specimen holder and associated apparatus is given together with experimental results. In conjunction with the experimental apparatus an assessment of determinant and indeterminant errors is made. Although the determinant $3 \sigma$ uncertainty in the measured gap conductance, $\mathrm{H}_{\mathrm{g}}$, is the same as reported in a previous topical report (PNL-2696, NUREG/CR-0330; April 1979), the 3o uncertainty associated with reproducibility of measurement was determined to be greater than $12 \%$ especially at high gas pressures and temperatures. As a result, the $3 \sigma$ uncertainty in the reproducibility of measurement was selected as being most representative of the overall experimental error and is calculated for each datum in this study.

The $\mathrm{H}_{\mathrm{g}}$ results are found to depend on gas pressure, temperature, average mean-plane separation distance, and gas composition. The following general features were observed:

- $H_{g}$ decreases with increasing xenon or argon gas concentration at any given temperature and gas pressure.

- The gap conductance initially increases very rapidly with increasing gas pressure (i.e. gas density) over the range between 0.103 and $1 \mathrm{MPa}$. The rate of increase in $\mathrm{H}_{\mathrm{g}}$ with gas pressure over this range decreases with additions of xenon or argon gas or increasing gap separation for a helium atmosphere. For all atmospheres and gap separations studied, the rate of increase in $\mathrm{H}_{\mathrm{g}}$ with gas pressure over the same range increases with increasing temperature.

- $H_{g}$ exhibits a pronounced hump at gas pressures between 0.1 and $2 \mathrm{MPa}$ for the helium and helium-xenon atmospheres. The hump is most pronounced for 
helium at $D_{m p}=5.9 \mu \mathrm{m}$ at higher temperatures and progressively diminishes with decreasing temperature and/or argon addition. No hump is observed at elevated temperature (473K) or with increased argon content (both $48.21 \%$ or 100\%). The unusual behavior of $\mathrm{H}_{\mathrm{g}}$ with pressure is similar to reported behavior of the thermal conductivity of helium with gas pressure. Discussion of a mechanism to account for the observed behavior based on the nature of velocity, time, and space of the gas molecules is given.

- At higher gas pressures between 1 and $7 \mathrm{MPa}, \mathrm{H}_{\mathrm{g}}$ decreases with increasing gas pressure for both the helium and $\mathrm{He}: \mathrm{Xe}(89.6: 10.4)$ atmospheres at all temperatures. With the addition of Argon gas, however, $\mathrm{H}_{\mathrm{g}}$ exhibits no dependence on gas pressure for the He:Ar(51.79:48.21) gas composition. However, a linear increase with increasing gas pressure for the argon (100\%) atmosphere is observed and is in accordance with reported increases in the thermal conductivity of Argon between 1 and $7 \mathrm{MPa}$.

In this report the predicted gap conductance based on the "ideal" expression $H_{g}=K_{\text {gas }} /\left(d+g_{1}+g_{2}\right)$ and assuming $D_{m p}=d$ and $g_{1}=g_{2}$, is compared to the $\mathrm{H}_{g}$ results and found not to be in agreement. Use of the ideal gap conductance expression under these conditions is seen to under-estimate the value of $\mathrm{H}_{\mathrm{g}}$ results. A discussion of possible reasons for the differences between the observed and predicted behavior is made. In addition to experimental errors resulting from gaseous convection, a detailed examination of the ideal gap conductance expression reveals that the basic assumptions (upon which the ideal gap conductance expression is derived) are not valid for real surfaces in close proximity and/or contact. It appears plausible that the mechanism of heat transfer across an interface depends on the relative magnitudes of local areas where free molecular, transition, and continuum conductance occurs. If free molecular/transition conditions dominate then enhanced conductance can result from a reduction in the number of molecular encounters between molecules. If continuum conditions dominate then the general features of the gap conductance can be described by the ideal gap conductance expression. 
Based on the results of the study recommendations are made where future research should be directed to elucidate the mechanism(s) of gaseous heat transfer between the fuel:clad interface. The need for additional gap conductance data at high gas pressures and reduction of the scatter in results are considered necessary to understand and ultimately develop models for the mechanism(s) of gap conductance between real surfaces. 



\section{LIST OF ACRONYMS AND NOMENCLATURE}

a

$C_{p}$

$C_{v}$

$\mathrm{CLA} 1,2$

d

$D_{m p}$

$\mathrm{DUO}_{2}$

$f_{i}$

$g_{1,2}$

GC

GP

HFM

$\mathrm{Hg}_{\mathrm{g}}$

$\mathrm{H}_{\mathrm{T}}$

$\mathrm{H}_{\mathrm{TR}}$

ISM

$k_{1,2}$
Accommodation coefficjent as defined by Knudsen (12)

Specific heat at constant pressure $(\mathrm{J} / \mathrm{mole}-\mathrm{K})$

Specific heat at constant volume $(\mathrm{J} / \mathrm{mole}-\mathrm{K})$

Center-line average roughness for $\mathrm{DUD}_{2}$ and $\mathrm{Zr} 4$, respectively $(\mathrm{m})$

Ideal surface separation distance for perfectly smooth and flat surfaces

(m)

Average mean-plane separation distance [arithmetic average of all $\left.\left(D_{m p}\right)_{i}\right]$

Depleted Uranium Dioxide

Mole fraction of gas species " $i "$ in a gas mixture

Temperature jump distance at the $\mathrm{DUO}_{2}$ and $\mathrm{Zr} 4$ surfaces, respectively (m)

Gas composition

Fluid (gas) pressure (Pascals)

Gap conductance in the free-molecular flow regime $\left(\mathrm{W} / \mathrm{m}^{2}-\mathrm{K}\right)$

Gap conductance $\left(W / m^{2}-K\right)$

Total conductance across an interface $\left(W / m^{2}-K\right)$

Total gas conductance in the transition regime

Interfacial surface morphology

Thermal conductivity of $\mathrm{DUO}_{2}$ and $\mathrm{Zr4}$, respectively 


\begin{tabular}{|c|c|}
\hline $\mathrm{K}_{\text {gas }}$ & Thermal conductivity of a gas $(\mathrm{W} / \mathrm{m}-\mathrm{K})$ \\
\hline KN & Knudsen number \\
\hline$M_{j}$ & $\begin{array}{l}\text { Molecular weight of atomic species } \\
\text { " }{ }^{\prime \prime}\left(\mathrm{K}_{\mathrm{g}} / \mathrm{mole}\right)\end{array}$ \\
\hline MPD & Modified Pulse Design \\
\hline $\mathrm{T}$ & Temperature $(\mathrm{K})$ \\
\hline$T_{\text {gas }}$ & Gas temperature $(\mathrm{K})$ \\
\hline$T_{1,2}$ & $\begin{array}{l}\mathrm{DUO}_{2} \text { and } \mathrm{Zr} 4 \text { surface temperatures } \\
(\mathrm{K})^{2}\end{array}$ \\
\hline TJD & Temperature Jump Distance \\
\hline $\mathrm{Zr} 4$ & Zircaloy -4 \\
\hline$\alpha_{1,2}$ & $\begin{array}{l}\text { Thermal diffusivity of } \mathrm{DUO}_{2} \text { and } \\
\mathrm{Zr} 4 \text {, respectively }\left(\mathrm{m}^{2} / \mathrm{sec}\right)\end{array}$ \\
\hline$\Delta \mathrm{T}$ & $\begin{array}{l}\text { Temperature difference across an } \\
\text { interface }(K)\end{array}$ \\
\hline Y & Ratio of specific heats, $C_{p} / C_{v}$ \\
\hline$\left(\gamma_{1,2}\right)_{i}$ & $\begin{array}{l}\text { Local distance from optical gage } \\
\text { probe tip to the surface mean-plane } \\
\text { on the } \mathrm{DUO}_{2} \text { and } \mathrm{Zr} 4 \text { respectively } \\
\text { (m) }\end{array}$ \\
\hline$\Upsilon_{1,2}$ & $\begin{array}{l}\text { Arithmetic average of all } \\
\left(\gamma_{1}, 2\right)_{i} \text {, values }(m)\end{array}$ \\
\hline$\lambda$ & Mean free path of a gas molecule $(\mathrm{m})$ \\
\hline$\phi$ & $\begin{array}{l}\text { Tabulated shape factor depending on } \\
r_{1} / r_{2} \text { where } r_{1} \text { and } r_{2} \text { are the } \\
\text { surface roughness of the uranium } \\
\text { dioxide and zircaloy-4 respectively }\end{array}$ \\
\hline$\psi$ & $\begin{array}{l}\text { Total fractional uncertainty in the } \\
\text { average mean-plane separation } \\
\text { distance }=\psi_{R}+\psi_{E O F}\end{array}$ \\
\hline$\psi_{R}$ & $\begin{array}{l}\text { Fractional uncertainty in the average } \\
\text { mean-plane separation distance due to } \\
\text { the surface roughness }\end{array}$ \\
\hline
\end{tabular}




$\begin{array}{ll}\ell_{1,2} & \begin{array}{l}\text { Thickness of the } \mathrm{DUO}_{2} \text { and } \\ \text { zircaloy-4 specimens respectively }(\mathrm{m})\end{array} \\ \psi E \mathrm{EOF} & \begin{array}{l}\text { Fractional uncertainty in the average } \\ \text { mean-plane separation distance due to } \\ \text { the surface error-of-form }\end{array} \\ \theta_{\mathrm{I}} & \begin{array}{l}\text { Mean energy of a molecular stream } \\ \text { incident on a surface } \\ \text { (joule/molecule) }\end{array} \\ \theta_{\mathrm{R}} & \begin{array}{l}\text { Mean energy of a molecular stream } \\ \text { reflected from a surface } \\ \text { (joule/molecule) }\end{array} \\ \theta_{W} & \begin{array}{l}\text { Mean energy of molecules within a } \\ \text { reflected stream that had reached } \\ \text { thermal equilibrium with the wall } \\ \text { (joule/molecule) }\end{array}\end{array}$




\section{CONTENTS}

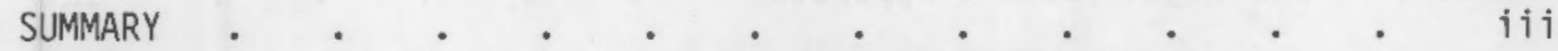

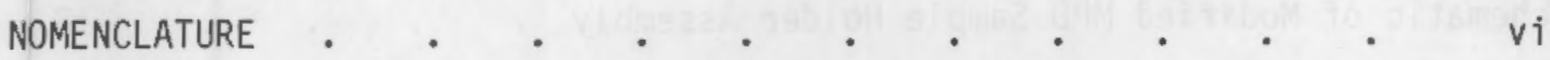

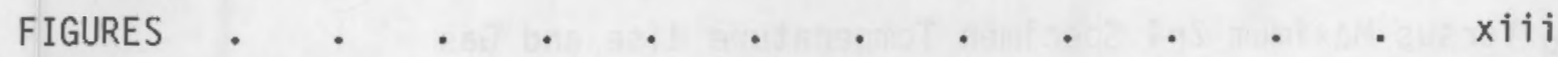

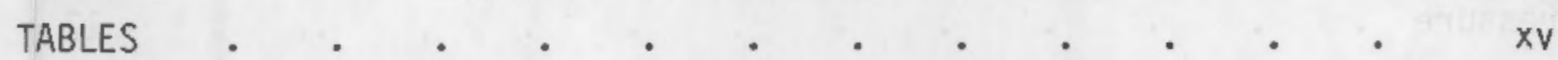

1.0 INTROOUCTION

2.0 PERSPECTIVE ON MODELING GAP CONDUCTANCE . . • . . 5

2.1 CONTINUUM . $\quad . \quad \cdot \quad \cdot \quad \cdot \quad \cdot \quad \cdot \quad \cdot \quad \cdot \quad \cdot \quad 5$

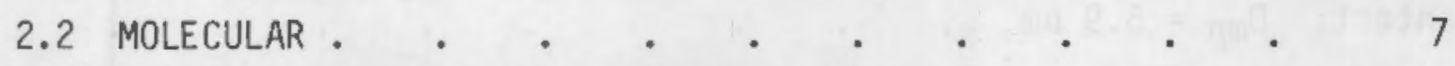

3.0 EXPERIMENTAL EQUIPMENT ANO PROCEDURES . . . . . . . 11

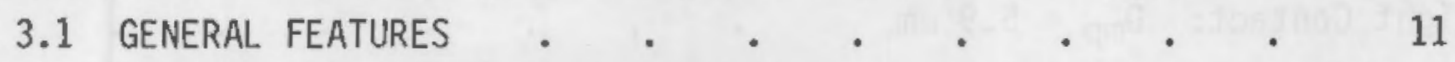

3.2 DETERMINATE/INOETERMINATE ERRORS.$\quad \cdot \quad \cdot \quad \cdot \quad \cdot \quad 14$

3.3 SAMPLE PREPARATION AND CHARACTERIZATION . . . . 18

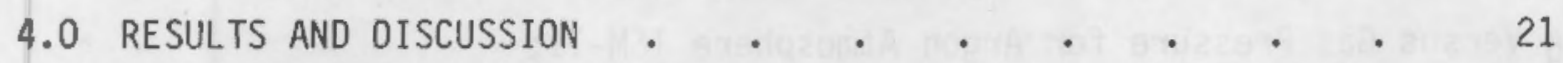

4.1 GAP CONDUCTANCE RESULTS • • . . . . . . 21

4.2 COMPARISON OF $\mathrm{H}_{\mathrm{g}}$ TO THE IDEAL GAP CONDUCTANCE EXPRESSION 27

5.0 CONCLUSIONS AND RECOMMENDATIONS . . . . . . . . . 35

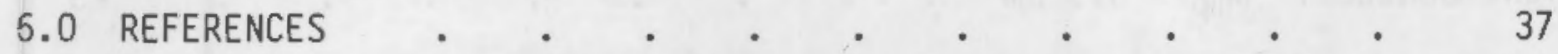

APPENDIX A - MPD EXPERIMENTAL DATA . • • • • • • A. A.I

APPENDIX B - SURFACE CHARACTERIZATION OF MPD SPECIMEIIS . • B.I 


\section{FIGURES}

1 Schematic of MPD High Pressure Apparatus . . . . . 12

2 Schematic of Modified MPD Sample Holder Assembly . . . . 13

$3 \mathrm{Hg}$ Versus Maximum $\mathrm{Zr} 4$ Specimen Temperature Rise and Gas Pressure . . . . . . . . . . . . 17

4 Zr4 Back-Surface Temperature Fluctuations as a Function of Time . . . . . . . . . . 18

$5 \quad \mathrm{Hg}_{\mathrm{g}}$ Versus Gas Pressure for Helium Atmosphere ISM-II; Light

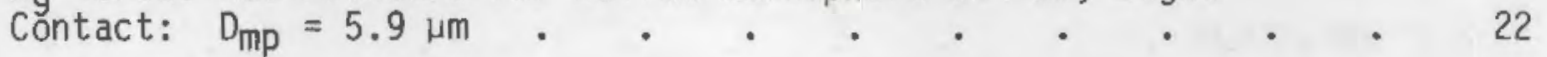

$6 \quad H_{g}$ Versus Gas Pressure for He:Xe Atmosphere ISM-II; Light Contact: $\mathrm{D}_{\mathrm{mp}}=5.9 \mu \mathrm{m}$. . . . . . . 23

$7 \quad \mathrm{H}_{\mathrm{g}}$ Versus Gas Pressure for He:Ar Atmosphere ISM-II; Light Contact: $D_{m p}=5.9 \mu \mathrm{m}$. . . . . . . 23

$8 \mathrm{Hg}_{\mathrm{g}}$ Versus Gas Pressure for Argon Atmosphere ISM-II; Light Contact: D Dp $5.9 \mathrm{~lm}$. . . . . . . . 24

$9 \quad \mathrm{H}_{\mathrm{g}}$ Versus Gas Pressure for $\mathrm{He}(100), \mathrm{He}(89.4): \mathrm{Xe}(10.6)$, Hê(51.79): $\operatorname{Ar}(48.21)$ and $\operatorname{Ar}(100)$ Atmosphere at 283K, ISM-II;

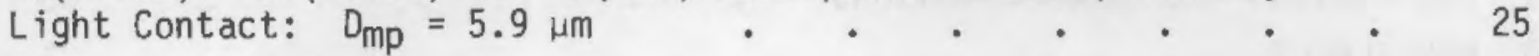

$10 \mathrm{Hg}_{\mathrm{g}}$ Versus Gas Pressure for $\mathrm{He}(100), \mathrm{He}(89.4): \mathrm{Xe}(10.6)$, He(51.79): $\operatorname{Ar}(48.21)$ and $\operatorname{Ar}(100)$ Atmospheres at 473K, ISM-II; Light Contact: $D_{\mathrm{mp}}=5.9 \mathrm{\mu m}$. . . . . . . 25

$11 \mathrm{Hg}$ Versus Gas Pressure for Helium Atmosphere ISM-II; $D_{\mathrm{mp}}=21.3 \mu \mathrm{m} \quad \cdot \quad \cdot \quad \cdot \quad \cdot \quad \cdot \quad \cdot \quad \cdot \quad \cdot \quad 27$

$12 \mathrm{Hg}_{\mathrm{g}}$ Versus Gas Pressure for Helium Atmosphere. Comparison of Results to Ideal Gap Conductance Expression $D_{\mathrm{mp}}=5.9 \mu \mathrm{m}$. . 30

$13 \mathrm{Hg}$ Versus Gas Pressure for Argon Atmosphere. Comparison of Results to Ideal Gap Conductance Expression, $D_{\text {mp }}=21.3 \mu \mathrm{m}$. . 31

$14 \mathrm{H}_{\mathrm{g}}$ Versus Gas Pressure for Helium Atmosphere. Comparison of Results to Ideal Gap Conductance Expression, $D_{m p}=21.3 \mu \mathrm{m}$

15 Thermal Conductivity of Helium Gas Versus Pressure as Reported by Ho and Leidenfrost . . . . . . . . . . 33 


\section{TABLES}

1 Equations for Temperature Jump Distance . . . . . . 6

2 Compositions and Impurity Analysis for Gases Used in MPD Experiments $\quad . \quad$. $\quad . \quad$. . . . . . . . . 13

3 Determinate Errors in MPD Experiment . . . . . . 15

4 Indeterminate Errors in MPD Experiment . . . . . . . 16 



\subsection{INTRODUCTION}

The previous topical report ${ }^{(1)}$ involved an ex-reactor study of the effects of temperature (T), gas composition (GC), interfacial surface morphology (ISM), and mean-plane of separation distance $\left(D_{m p}\right)$ on the thermal gap and contact conductance between depleted uranium dioxide $\left(\mathrm{DUO}_{2}\right)$ and Zircaloy-4 (Zr4).

A detailed description of two developed measurement techniques [the Modified Pulse Design (MPD), a transient technique, and the Modified Longitudinal Design (MLD), a steady-state technique] was given along with information related to sample preparation, thermal property determination, surface characterization and determination of $D_{m p}$. Review of previous in-reactor and ex-reactor gap conductance experimentation was made and a discussion presented covering heat transfer formulations, gap geometry, and selected calculational models for estimating the gap $\left(H_{g}\right)$ and solid:solid contact $\left(H_{C}\right)$ conductance contributions to the total heat transfer between the fuel:clad surfaces. In reference to the thermal gap conductance between $\mathrm{DUO}_{2}$ and $\mathrm{Zr} 4$, the report ${ }^{(1)}$ concluded that: 1) $\mathrm{H}_{g}$ exhibits a dependence on $T, G C$, ISM, and $D_{m p}$; 2) the observed two-factor interactions between $D_{m p}-T, D_{m p}-G C, D_{m p}-I S M, T-G C$, and T-ISM demonstrate that the gap conductance is not uniquely related to the physical separation distance when the total fractional uncertainty in $D_{m p}$ is greater than 0.1. Stated differently, the same value of "gap conductance" can result at various gap distances by virture of differences in surface roughness and/or error of form alone; and, 3) allowance for the imperfect thermal accommodation between gap molecules and surfaces must be made. The latter point is significant in that in-pile experimentation has shown fuel relocation to be an operative mechanism within the fuel rod, (2-4) indicating that a smaller fuel:clad gap may be present. This conclusion places greater importance in accounting for the imperfect exchange between gas molecules and surfaces, i.e., the accommodation coefficient.

The "ideal" gap conductance expression is given by

$$
H_{g}=K_{g a s} /\left(d+g_{1}+g_{2}\right)
$$


where $d=$ the ideal surface separation distance for perfectly smooth and flat surfaces (m);

$k_{\text {gas }}=$ thermal conductivity of the fill gas $(W / m-K)$; and

$g_{1}$ and $g_{2}=$ temperature jump distances at the $\mathrm{DUO}_{2}$ and $\mathrm{Zr} 4$ surfaces, respectively,

This expression assumes that $D_{m p}=d$ and $g_{1}=g_{2}$ for various definitions of the separation distance between two surfaces and temperature jump distance models (e.g., Kennard, ${ }^{(5)}$ Lloyd, ${ }^{(6)}$ and GAPCON THERMAL II and III ${ }^{(7,8)}$ ). Comparison of predicted and experimental $\mathrm{H}_{9}$ results showed that an underest imated value for $\mathrm{H}_{g}$ would result if the GAPCON THERMAL III fuel performance code ${ }^{(8)}$ algorithms for computing the gas conductivity and temperature jump distances were used.

Equation (1) ${ }^{(a)}$ was compared to the free molecular flow gap conductance expression (valid as $d$ approaches zero).

$$
H_{g}=H_{F M}=\frac{G P}{4}\left(\frac{2 R}{\pi}\right)^{1 / 2}\left(\frac{Y+1}{Y-1}\right)-\frac{1}{\sqrt{T}}\left(\frac{a}{2-a}\right)
$$

where $G P=$ pressure $\left(P_{a}\right)$

$$
\begin{aligned}
& R=\text { gas constant }(8.31 \mathrm{~J} / \mathrm{mole}-K) \\
& Y=\text { ratio of specific heats, } C_{p} / C_{v} \\
& T=\text { temperature }(K) \\
& a=\text { accommodation coefficient }
\end{aligned}
$$

Any inconsistencies in the manner of convergence appeared to be masked by surface roughness effects at values of $D_{m p}$ less than $25 \mu m(1 \mathrm{mil})$ at least within the determinant $3 \sigma$ uncertainties of $\mathrm{H}_{g}$ and $\mathrm{D}_{\mathrm{mp}}$.

The objective of this study was to extend $H_{g}$ measurements to gas pressures above atmospheric to obtain information on the effects of temperature, gap separation, and gas composition on $\mathrm{H}_{g}$ at varying gas pressures. In

(a) Using the Kennard model(5) for describing the temperature jump distance. 
addition to the need for accurate high pressure data, the determination of the sensitivity of $\mathrm{H}_{\mathrm{g}}$ to changes in these variables would allow for further refinement of oxide fuel performance codes such as GAPCON-THERMAL, $(7,8)$ COMETHE, ${ }^{(9)}$ FRAPCON, ${ }^{(10)}$ and IAMBUS. (11) 



\subsection{PERSPECTIVE ON MODELING GAP CONDUCTANCE}

The process of heat transfer via conduction through a gas interface can be viewed from two different perspectives. From a macroscopic viewpoint heat is transferred from a region of higher temperature to a region of lower temperature in a medium (i.e., a gas). From a microscopic viewpoint, the process of heat transfer can be viewed as occurring through exchange of kinetic energy between molecules. The contrast between the macroscopic and microscopic viewpoints is reflected in the approach applied to modeling of a particular heat transfer problem.

\subsection{CONTINUUM}

The basic assumption in this method of modeling is that the medium through which heat is transferred is a continuum. This means that the mean free path, $\lambda$, of the gas molecules is considered to be small in relation to all other dimensions existing in the medium such that a statistical average is possible, i.e., collisions between molecules in free space will be distributed in an irregular manner but over a sufficient period of time to include a large number of molecular encounters so that on the average a definite number of collisions will occur each second.

Gap conductance models used in various fuel performance codes ${ }^{(7-11)}$ are based on the assumption that a continuum is always present in the fuel:clad gap, i.e., Fourier's law of heat conduction is valid. The concept of the temperature jump distance (TJD) has been developed ${ }^{(a)}$ to account for the effects of imperfect energy transfer between gas molecules and the fuel and cladding surfaces, which become significant during fuel:clad gap closure. The TJD models can be summarized in the following generalized format:

$$
g_{i}=\frac{C \cdot K_{\text {gas }} \sqrt{T_{\text {gas }}}}{G P} F\left(a_{i}, f_{i}, M_{i}\right) \text { meters }
$$

where $i=1,2$ standing for the fuel and clad, respectively $C=$ constant

(a) As treated by Knudsen (12) and subsequently defined by Kennard ${ }^{(5)}$, Lloyd $(6)$, and more recently Loyalka(13). 
$F=$ function of the thermal accommodation coefficient $a_{j}$; mole fraction, $f_{i}$; and molecular weight, $M_{i}$ of gas species $i$ ( $\mathrm{kg} / \mathrm{mole})$

$\mathrm{GP} \quad=$ gas pressure $(\mathrm{Pa})$

$T_{\text {gas }}=$ mean gap temperature $\left(T_{1}+T_{2}\right) / 2(K)$

$K_{\text {gas }}=$ thermal conductivity of the gas mixture $(W / m-K)$.

Table 1 lists the constant $C$ and the function $F$ for the theoretical models of Lloyd, Kennard, and Loyalka. In addition, the expression used in the GAPCON-THERMAL II fuel performance code is also listed. The latter uses the Lloyd model which has been modified by an empirical correction factor.

\section{TABLE 1. Equations for Temperature Jump Distance}

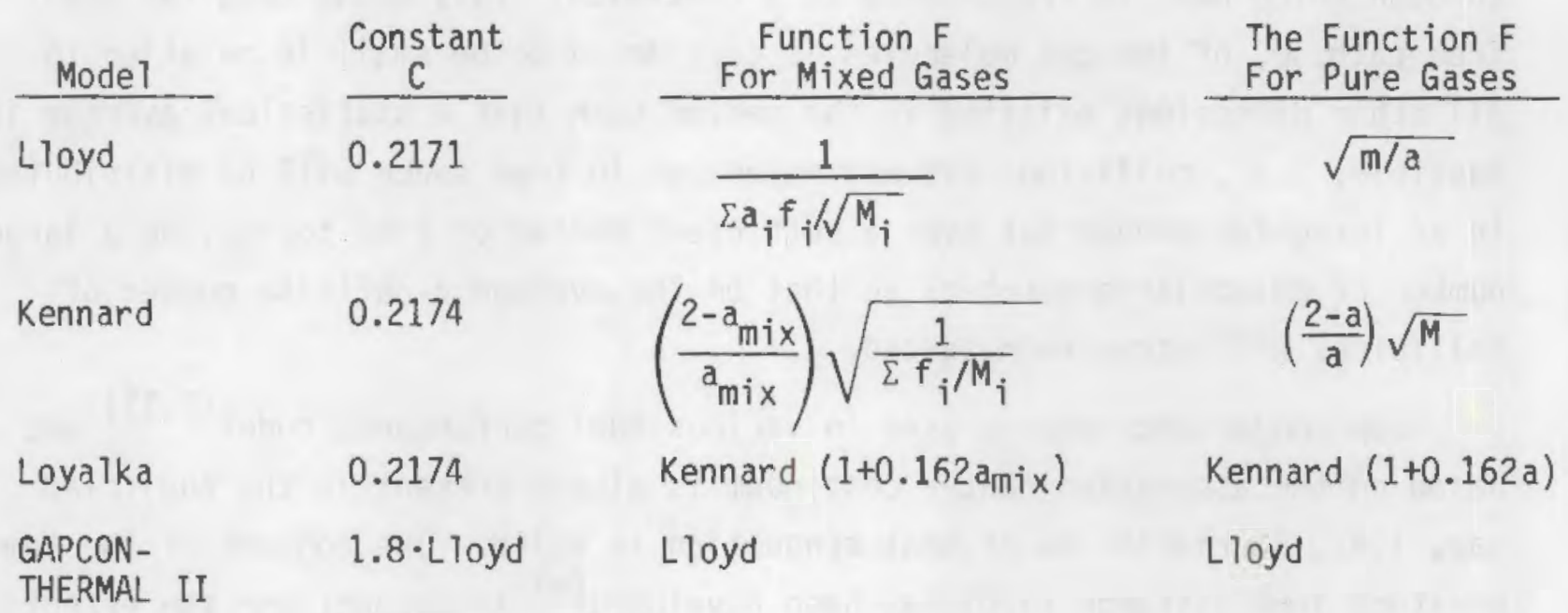

The models differ from each other in two aspects: first, in the manner in which they consider mixed gases; and, secondly, in the way the accommodation coefficient enters the expression. Thus, the value of $\mathrm{H}_{\mathrm{g}}$ computed on the basis of Equation 1 will depend on the TJD model and the particular expressions employed for $K_{g a s}$ and $a$. It was emphasized previously ${ }^{(1)}$ that Equation 1 is only appropriate under conditions where the correct TJD model is known and the Knudsen number (KN) as defined by

$$
K N=\frac{\lambda}{\text { Gap Distance }}
$$


is $<0.01$, and; the fractional uncertainty in the computed gap distances, (1), $\psi$, is $\ll 0.1$. The factor $\psi$ arises due to the surface roughness and/or error of form associated with the surface and is defined as

$$
\psi=\frac{\theta \cdot \mathrm{CLA}_{1}+\theta \cdot \mathrm{CLA}}{2}
$$

(where $\theta$ is a constant having a value of 5 for a "uniformly random" surface and CLA is the respective center line average surface roughness values).

Clearly, when conditions within the fuel:clad gap are such that KN $>0.01$ and $\psi \gtrsim 0.1$ or both, the medium within the gap (i.e gas) can no longer sustain a temperature gradient. Thus the basic assumption of a continuum being present within the fuel:clad gap is no longer valid and extrapolations based on Equation 1 become questionable. For example, it has been demonstrated (1) that use of Equation 1 (with the restrictive assumptions that $D_{m p}=d$, and $\left.g_{1}=g_{2}\right)$ under conditions where $K N \gtrsim 0.01$ and $\psi \gtrsim 0.1$ leads to an underestimated value for $\mathrm{H}_{g}$ when compared to the experimental results of that study.

\subsection{MOLECULAR}

In contrast to the continuum perspective, the microscopic viewpoint requires that consideration be given to the behavior of molecules on an atomistic scale. Solving the many bodied system in both time and space involves dealing with mathematical difficulties, as well as the intermolecular forces between molecules and solid surface atoms.

From the perspective of two real surfaces in close proximity, i.e., where the free path of the molecules are on the same dimensional scale as the distance of separation between the solid surfaces, both the spatially distributed molecular structure, as well as the kinetic energy exchange between solid surface atoms and molecules, will determine the transfer of energy (i.e. gap conductance) between the solid surfaces. Under these conditions the free path lengths of individual molecules are bounded in the lower limit by the normal spatial distance between solid surface atoms and in the upper limit by virtue 
of the proximity of the solid surfaces. Likewise collisions between molecules in free space regions will be distributed in an irregular manner but over a sufficient period of time include a large number of molecular encounters so that on the average a definite number of collisions will occur each second i.e., classical gas theory. Thus, it is plausible that when two solid surfaces are in close proximity the interface can consist of localized areas where free molecular, transition, and continuum conditions will be present simultaneously within the interface.

Given a local area at the interface where a large fraction of molecules can encounter solid atoms at opposite surfaces numerous times before encounting another gas molecule, the transfer of energy will be dominated by the energy exchange between gas molecules and surface atoms alone. The free-molecular conductance under these conditions does not have the same meaning as described by Equation 2 insofar as the physical meaning of the accommodation coefficient is not the same as defined by Knudsen (12) nor as applied by Kennard $(5)$ and Lloyd ${ }^{(6)}$ in their development of the theory of the temperature jump distance(i.e., as regards convergence of the ideal gap conductance expression in the limit as $d \rightarrow 0$ to a free molecular expression for gap conductance).

As defined by Knudsen, the accommodation coefficient is

$$
a=\frac{\theta_{I}-\theta_{R}}{{ }^{\theta_{I}-{ }^{\theta} W}} \quad \text { where } 0 \leq a \leq 1
$$

where $\theta_{I}=$ mean energy of the incident molecules

$\theta_{R}=$ mean energy of the reflected molecules

$\theta_{W}=$ mean energy of the reflected molecules if they were to reach thermal equilibrium with the wall.

It is assumed that the incident molecules arrive from a source (i.e., gaseous medium) which is a continuum. (14) Clearly, in local areas of the interface where free-molecular conditions exist, this assumption is not valid. Examination of this point has been made by others ${ }^{(19-20)}$ where, 
in particular, (20) it was shown that the translational accomodation coefficient, as defined by Equation 6 , was found to be outside the interval 0-1 for helium, nitrogen, and hydrogen gases on test surfaces of tungsten, platinum, and aluminum. Measurements of accommodation coefficients greater than 1 have also been recently reported ${ }^{(21)}$ for Zircaloy-2 test surfaces.

When the free path length of a molecule is of the same order as the distance between surfaces, a coupling will exist between the incident and reflected energy of the molecule between surfaces. Although the nature of the accomodation coefficient via freely translating molecules under these conditions is not presently known, some insight into the behavior of the gap conductance can be gained by examining the velocity behavior of a molecule in time and space.

The time required for a molecule to complete a round $t r i p$ between two surfaces depends upon its velocity and total distance of travel. Assuming a constant velocity, the round trip time will be reduced in direct proportion to a reduction in the distance traveled. Thus, a molecule traveling at a constant velocity is capable of transmitting a greater amount of energy per unit time across small distances than across large distances.

Given initially free molecular conditions within a local area at an inter$f$ ace, where the distance between surfaces is fixed and a temperature difference between surfaces is present, an increase in the number of molecules (i.e., gas density) will cause a proportional increase in the energy transmitted per unit time provided that the molecules do not encounter one another during the round trip between surfaces. With continued increases in the gas density, the number of molecular encounters will increase resulting in an increase in the round trip distance traveled by the molecules and subsequently may result in a decrease in the energy transported per unit time. A continued decrease in the energy transmitted per unit time will occur until a gas density is achieved whereby a sufficient number of molecular encounters results in the establishment of a continuum within the local area. The nature of the continuum resides in the directional velocities of molecules in space as a result of the different temperature regions which originate from the temperature differences between the surfaces. 
Given two surfaces in close proximity the behavior of the gap conductance will, with increasing gas density depend upon whether free molecular, transition, or continuum conditions exist. If free molecular conditions dominate then the manner in which the conductance behaves as a function of increasing gas density will depend on the nature and behavior of the "coupling" between surfaces via freely translating molecules. If continuum conditions dominate then the behavior of the conductance would be as described in the previous section. 


\subsection{EXPERIMENTAL EQUIPMENT AND PROCEDURES}

\subsection{GENERAL FEATURES}

The MPD technique is a modification of the classical heat pulse (flash) method commonly used to determine the thermal diffusivity and conductivity of materials. (22) In the MPD technique, a laser is used to supply a heat pulse to the front face of a $\mathrm{DUO}_{2}-\mathrm{Zr} 4$ sample pair which is in light contact or separated by a gap. The subsequent temperature $r$ ise on the back face of the $\mathrm{Zr} 4$ sample is then monitored by an intrinsic fast response thermocouple. From this transient temperature and knowledge of the thermal properties of the respective specimens, the thermal gap conductance can be determined as a function of such variables as temperature, mean-plane gap width, gas composition, and gas pressure. For this study an autoclave was designed and constructed to accommodate gas pressures up to $14 \mathrm{MPa}$ in order to investigate the effects of high gas pressures on $\mathrm{H}_{\mathrm{g}}$.

The high pressure MPD experimental test apparatus is shown schematically in Figure 1. The sample pair is illuminated on the front face of the $\mathrm{DUO}_{2}$ sample with a laser pulse ( 30 joule maximum output; $800 \mu \mathrm{sec}$ pulse duration); and, the resultant temperature transient on the back surface of the $\mathrm{Zr} 4$ specimen monitored by a $25.4 \mu \mathrm{m}$ diameter Chromel-Constantan (type E) intrinsic thermocouple spot welded near the center of the disc.

The resulting emf output of the thermocouple is amplified by a differential de pre-amplifier (gain $\approx 3050$ ) and recorded using a transient waveform recorder. The transient temperature curve is then displayed on an oscilloscope for visual inspection prior to transmission of the digitized wave form to a computing system for storage and analys is.

The MPD high pressure apparatus allows for the use of assorted gases at various pressures from atmospheric to $14 \mathrm{MPa}$. In addition, the system also provides for evacuation of the test chamber for gaseous backfilling operations and for the removal of residual oxygen from the gas supply. The gases used in this study consisted of helium(100), He:Ar (51.79:48.21), argon (100), and 


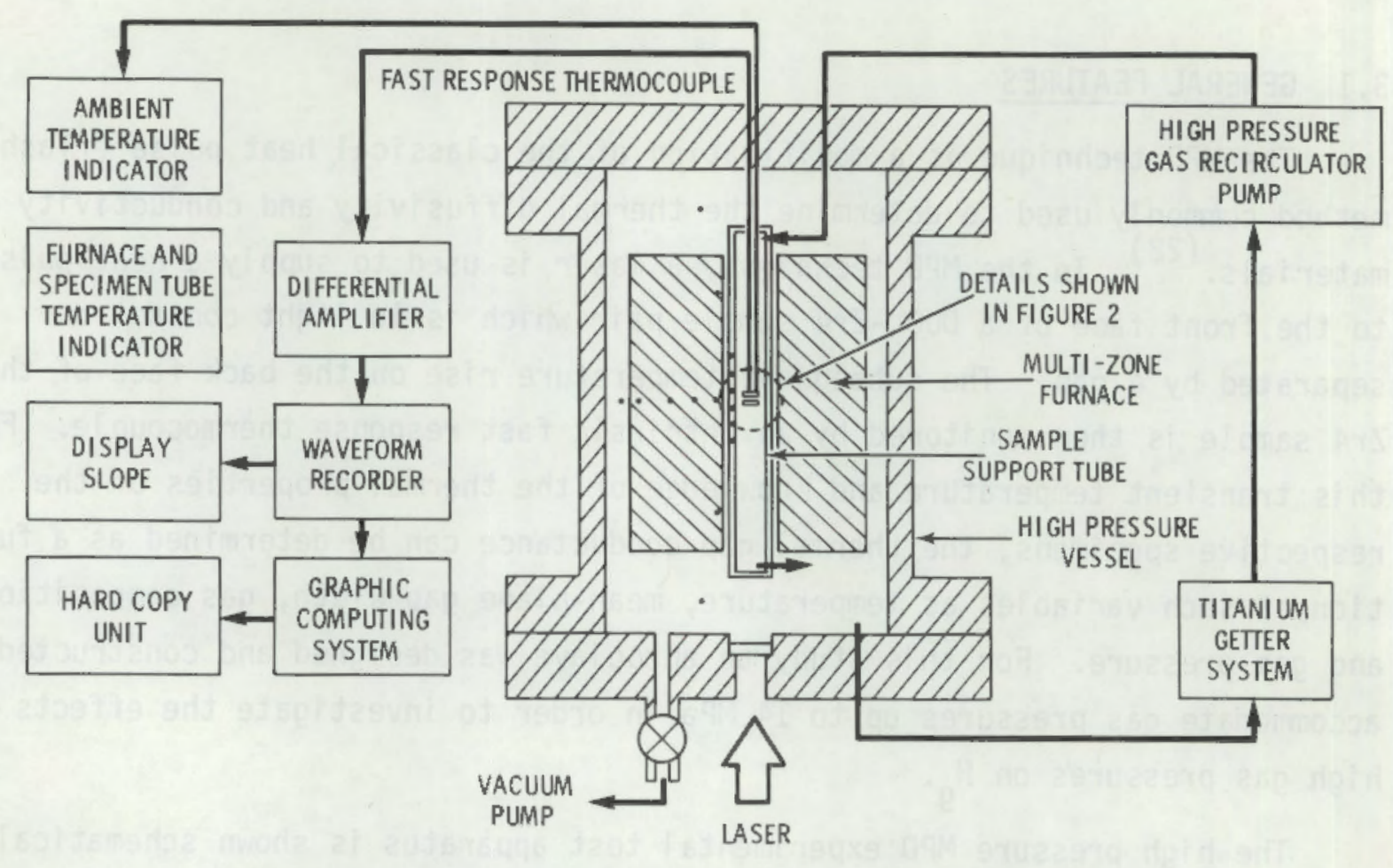

FIGURE 1. Schematic of MPD High Pressure Apparatus

He:Xe $(89.4: 10.6)$. The gases were premixed and analyzed as to composition and purity. A list of the gas compositions and purity analyses used in the MPD measurements can be found in Table 2. Due to the affinity of Zircaloy for oxygen at elevated temperatures, care was taken to assure removal of residual oxygen from the gas. An oxygen-free atmosphere was continually maintained by passing the gas through a zirconium gettering system before recirculating the gas by means of a high pressure diaphram-type pump. Further gettering was obtained within the specimen chamber by the placement of sacrificial zirconium sheets in proximity to the specimens and specimen holder. The gas pressure within the enclosure vessel was measured using a test gage accurate to $0.5 \%$.

As illustrated in Figure 2, a fixed gap width was maintained between the $\mathrm{DUD}_{2}$ and $\mathrm{Zr} 4$ specimens by three stainless steel spacers spot welded to the outer Zr4 support ring. A notched groove machined in the periphery of the Zr4 specimen was employed to minimize thermal shunting through the spacers during the measurement period following the absorption of the laser pulse on the front surface of the $\mathrm{OUO}_{2}$. 
TABLE 2. Compositions and Impurity Analys is for Gases Used in MPD Experiments

\begin{tabular}{|c|c|c|c|c|}
\hline Gas Composition & Analysis & Grade & $\begin{array}{l}\text { Purity } \\
\text { (min) } \\
\end{array}$ & Impurity Content \\
\hline Helium (100) & 99.99 min & Ultrapure & 99.999 & -- \\
\hline Argon $(100)$ & $\begin{array}{l}99.999 \\
99.999\end{array}$ & $\begin{array}{l}\text { U1trapure } \\
\mathrm{O}_{2} \text {-free grade }\end{array}$ & $\begin{array}{l}99.999 \\
99.999\end{array}$ & 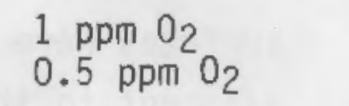 \\
\hline
\end{tabular}

He:Ar 51.79

48.21

\begin{tabular}{|c|c|c|c|c|c|}
\hline \multirow{3}{*}{ He:Xe } & & $\begin{array}{l}51.79 \% \mathrm{He} \\
\text { Balance Ar }\end{array}$ & $\begin{array}{l}\text { U1trapure } \\
\text { U1trapure }\end{array}$ & $\begin{array}{l}99.999 \\
99.999\end{array}$ & -- \\
\hline & $\begin{array}{l}89.4 \\
10.6\end{array}$ & $\begin{array}{l}10.2 \% \mathrm{Xe} \\
\text { Balance He }\end{array}$ & $\begin{array}{l}\text { Research Grade } \\
\text { Ultrapure }\end{array}$ & $\begin{array}{l}99.995 \\
99.999\end{array}$ & -- \\
\hline & & $\begin{array}{l}11.0 \% \text { Xe } \\
\text { Balance He }\end{array}$ & $\begin{array}{l}\text { Research Grade } \\
\text { Ultrapure }\end{array}$ & $\begin{array}{l}99.995 \\
99.999\end{array}$ & \\
\hline
\end{tabular}

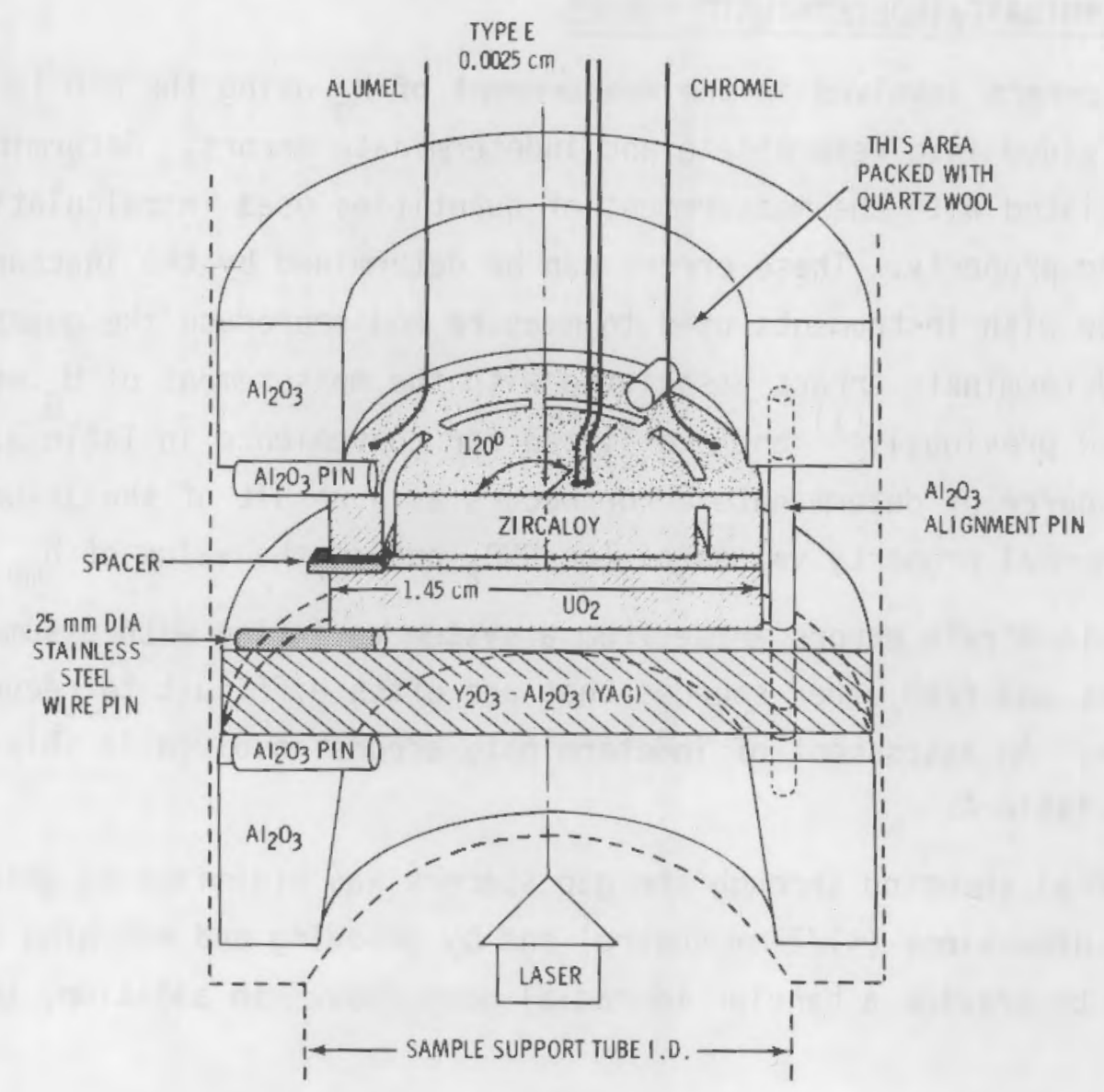

FIGURE 2. Schematic of Modified MPD Sample Holder Assembly 
Heat losses to the specimen holder during the passage of the transient heat pulse were minimized by supporting the $\mathrm{DUO}_{2}$ and $\mathrm{Zr} 4$ samples at the respective front and back faces by three equally spaced alumina pins. Heat losses occurring as the result of gaseous convection at the $\mathrm{DUO}_{2}$ and $\mathrm{Zr} 4$ surfaces were minimized by placement of a window (yttrium-aluminum garnet) adjacent to the front surface of the $\mathrm{DUO}_{2}$ and by packing the free space immediately adjacent to the back surface of the Zr4 sample with quartz wool. A multizone furnace was used to control the temperature profile across the sample holder to minimize temperature gradients within the confines of the sample holder volume.

The ambient temperature of the specimen pair was determined by use of a $127 \mu \mathrm{m}$ diameter, chromel-alumel (type K) thermocouple spot welded on the perimeter of the $\operatorname{Zr} 4$ sample.

\subsection{DETERMINATE/INDETERMINATE ERRORS}

The errors involved in the measurement of $\mathrm{H}_{\mathrm{g}}$ using the MPD technique can be divided into determinate and indeterminate errors. Determinate errors are associated with the measurement of quantities used in calculating a particular property. These errors can be determined by the inaccuracies associated with instruments used to measure and reproduce the quantities. The various determinate errors assnciated with the measurement of $\mathrm{H}_{\mathrm{g}}$ were determined previously ${ }^{(1)}$ and are listed for convenience in Table 3 . The largest source of determinate error occurs as a result of the $3 \sigma$ uncertainty in the thermal property values of the $\mathrm{DUO}_{2}$ and in the value of $\mathrm{mp}_{\mathrm{mp}}$.

Indeterminate errors arise from a system variation with assumed boundary conditions and from other sources that are often difficult to recognize and eliminate. An assessment of indeterminate errors involved in this study is given in Table 4 .

Thermal shunting through the gap spacers was minimized by using spacers of small dimensions ( $21 / 2 \mathrm{~mm}$ square) and by grooving and notching the $\mathrm{Zr} 4$ specimen to provide a barrier to radial heat flow. In addition, the spacers 
TABLE 3. Determinate Errors in MPD Experiment

\begin{tabular}{|c|c|c|}
\hline Determinate Error & $\begin{array}{c}\% \text { Uncertainty, } \\
+30\end{array}$ & Comments \\
\hline$\ell_{1}$ and $\ell_{2}$ & 2 & $\begin{array}{l}\text { Dependent on error of form. } \\
\text { Corrected for thermal expansion } \\
\text { effects. }\end{array}$ \\
\hline$k_{1}$ and $k_{2}$ & 4 & $\begin{array}{l}\text { Measured quantities or generated } \\
\text { from } C_{p} \text { and thermal diffusivity } \\
\text { data. }\end{array}$ \\
\hline$\alpha_{1}$ & 12 & Measured results on four samples. \\
\hline$\alpha_{2}$ & 5 & Measured. \\
\hline T & 0.5 & Calibrated type $K$ thermocouples. \\
\hline $\begin{array}{l}\text { Temperature-Time } \\
\text { Wavef orm }\end{array}$ & 0.6 & $\begin{array}{l}\text { Transient waveform recorder used in } \\
\text { recording and computer analys is of } \\
\text { waveform. }\end{array}$ \\
\hline$D_{m p}$ & $7-144$ & $\begin{array}{l}\text { Dependent on uncertainties in } \gamma_{1,2} \text { values, } \\
\text { and magnitude of } 0_{\mathrm{mp}} \text {. }\end{array}$ \\
\hline
\end{tabular}

were placed in positions relative to the grooves that would maximize the thermal path length from the spacer to the fast response thermocouple. Heat losses to the sample holder were minimized by utilizing line contact supports on $\mathrm{Al}_{2} \mathrm{O}_{3}$ pins. The effectiveness of these measures was demonstrated by the absence of any significant thermocouple output over a 10 second interval when a sample pair separated by a gap was pulsed under vacuum (2.67Pa) conditions.

The previous study ${ }^{(1)}$ concluded that thermal shunting through the spacers, heat losses to the sample holder, and laser-induced thermal buckling of the $\mathrm{DUO}_{2}$ spec imen were potentially the largest source of indeterminant uncertainty in the experiment. The high pressures encountered in the present study made gaseous convection the area of major concern. 


\section{TABLE 4. Indeterminate Errors in MPD Experiment}

Indeterminate Error

Gaseous convection

Radial heat losses occurring during measuring period.

Thermal shunting by spacers and heat losses to specimen holder.

Sample deflection occurring as result of absorbed laser heat pulse on front sample.

Extraneous radiation.

True interface boundary
Comments

Minimized by reduction of temperature gradient within sample holder; shield $\mathrm{DUO}_{2}$ and $\mathrm{Zr} 4$ specimens from convection currents. (i.e. use of optical window (YAG) in front of $\mathrm{DUO}_{2}$ specimen, Figure 2).

Depending on sample thickness and gap separation; minimized by reducing specimen thickness and maximizing specimen diameters.

Minimized by groove and notching of Zircaloy sample. Also, each sample is supported on $\mathrm{Al}_{2} \mathrm{O}_{3}$ pins.

The effect on $\mathrm{H}_{\mathrm{g}}$ was found to be negligible.

Reduced by radiation shielding.

Dependent on sample surface deviation from averaged interfacial planes of separation.

The effects of gaseous convection were minimized by using a multi-zone furnace and modifying of the sample holder assembly. An assessment of the effectiveness of these design features was made on the basis of the following system performance observations:

- Of concern was the effect that convection currents about the $\mathrm{DUO}_{2}$ and Zr4 specimens may have on the temperature-time history curve, occurring solely from the degree to which specimen temperatures departed from the sample holder temperature. An experiment was performed where $\mathrm{H}_{\mathrm{g}}$ was determined as a function of the maximum temperature $r$ ise on the back surface of the $\mathbf{Z r} 4$ specimen (obtained via variation in laser intensity level) at various gas pressures covering the range examined in this study. Figure 3 shows that $H_{g}$ is independent of the laser intensity within the $\pm 12 \%$ determinant error of experiment.

- The effects of convection current at high temperatures and gas pressures was assessed by monitoring of the base-line temperature at the back 


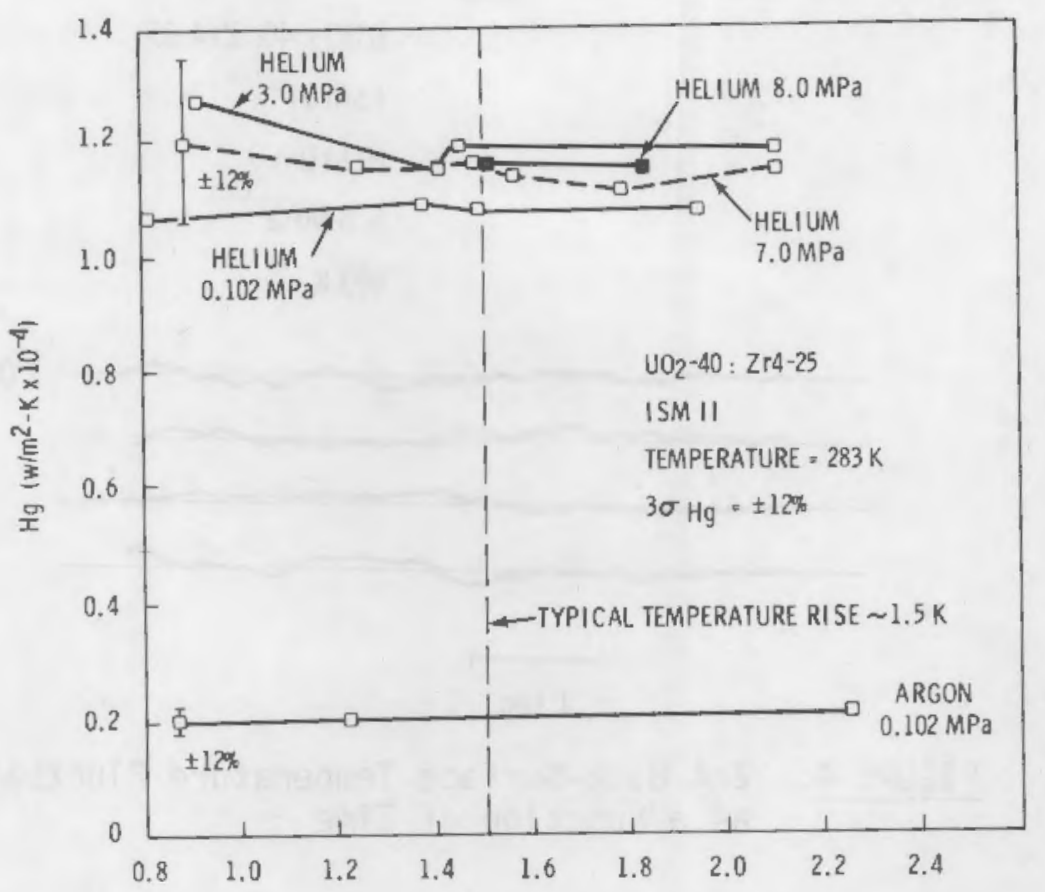

TEMPERATURE RISE ON BACK OF ZT4 SPECIMEN (K)

FIGURE 3. Hg Versus Maximum Zr4 Specimen Temperature Rise (1.e. Taser Intensity) and Gas Pressure

surface of the Zr4 sample prior to each measurement. A typical example of convection current noise at $693 \mathrm{~K}$ in an atmosphere of helium at $5.5 \mathrm{MPa}$ is shown in Figure 4 where base line temperature fluctuations at the back surface of the $\mathrm{Zr} 4$ sample are plotted versus time. The total time for firing the laser and capturing the temperature-time curve varied from approximately 0.5 to 2.0 seconds depending on experimental conditinns. However, the analog to digital recorder was capable of pre-trigger recording, making it possible to capture the prefiring noise for a visible inspection prior to analysis. The purpose of the visual inspection was to eliminate from analysis any curve whose temperature base line prior to firing of the laser showed a temperature variation greater than $0.02 \mathrm{~K}$ (as compared to a typical laser-induced temperature transient of approximately 1.5K, Figure 3). No attempt was made to collect data at temperatures and gas pressures when the pre-trigger base line temperature variation was greater than $0.02 \mathrm{~K}$. 
$\mathrm{DUO}_{2}-40: \mathrm{Zr} 4-25$

ISM II

HELIUM

$5.6 \mathrm{MPa}$

$693 \mathrm{~K}$

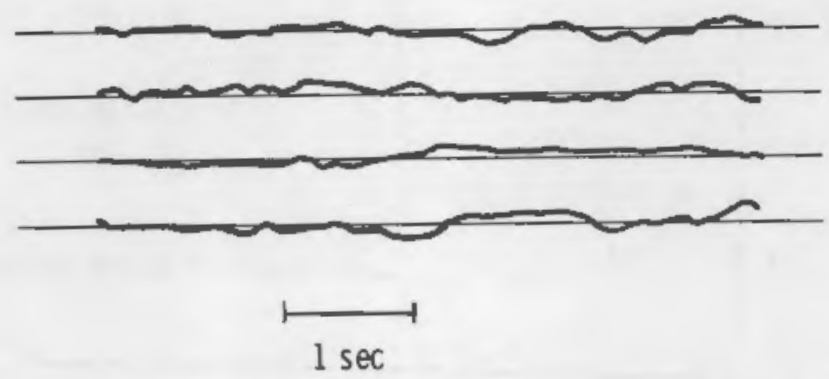

I $0.1 \mathrm{~K}$

FIGURE 4. Zr4 Back-Surface Temperature Fluctuations as a Function of Time

The effectiveness of the preceding data acquisition procedure was determined during the course of subsequent experimentation. Under conditions of both high gas pressure and temperature the reproducibility in $H_{g}\left(3 \sigma_{R}\right)$ was greater than the $3 \sigma$ determinate error in $H_{g}$. Inspection of the $H_{g}$ results in Appendix A will show that the $3 \sigma_{R}$ error increases with both increasing temperature and gas pressure. This result indicates that the effects of gaseous convection may not have been totally eliminated from the experiment. To account for the influence of gaseous convection, the $3 \sigma_{R}$ error was selected as being more representative of the degree of measurement uncertainty at each final experimental condition of temperature, gas composition, gas pressure and mean-plane of separation.

\subsection{SAMPLE PREPARATION AND CHARACTERIZATION}

The depleted $\mathrm{UO}_{2}$ and Zircaloy-4 specimens employed in this study were the Interfacial Surface Morphology-II (ISM-II) specimens $\left(\mathrm{OUO}_{2}-40\right.$ and Zr4-25) described previously. (1) The $\mathrm{DuO}_{2}$ and $\mathrm{Zr} 4$ surfaces were produced by grinding with 400 grit silicon carbide power in a nondirectional manner. Talysurf-4 profilometer measurements of surface roughness vielded center line average (CLA) values of $1.6 \pm 0.7 \mu \mathrm{m}$ and $0.4 \pm 0.2 \mu \mathrm{m}$ for the $\mathrm{DUO}_{2}$ and $\mathrm{Zr} 4$ 
specimens, respectively, at an instrument wavelength cutoff of $760 \mu \mathrm{m}$. The respective specimen thermal diffusivity, conductivity, and thermal expansion values at various temperatures were determined previously. (1)

The mating surface macrotopology of the $\mathrm{DUO}_{2}$ and Zircaloy-4 specimens were determined from a point-wise topographical surface map obtained using a point-wise optical height gauge measurement technique. (1) The surface characterization of the ISM-II specimens are described in Appendix B. 



\subsection{RESULTS AND DISCUSSION}

The MPD experiments have been conducted on an ISM-II sample pair as a function of temperature (283 to 673K), gas composition (helium; He:Xe(89.4:10.6); He:Ar(51.79:48.21) and argon), mean-plane width (5.9 and $21.3 \mu \mathrm{m})$, and gas pressure $(0.1 \mathrm{MPa}$ to $7.0 \mathrm{MPa})$. All the $\mathrm{H}_{\mathrm{g}}$ data meeting the base line temperature criteria (see section 3.2) and averaged results are listed in tabulated form in Appendix A. As the repeatability of measurement under certain experimental conditions was found to be greater than the absolute determinate $3 \sigma$ uncertainty $^{(1)}$ in $\mathrm{H}_{g}$ (i.e. $\pm 12 \%$ ), the $3 \sigma_{R}$ error was selected as being more representative of the overall uncertainty at each condition of experiment.

The mean-plane separation distance $\left(D_{m p}\right)$, and surface characterization information on the ISM-II specimens can be found in Appendix B.

\subsection{GAP CONDUCTANCE RESULTS}

The dependence of $\mathrm{H}_{g}$ on gas pressure is shown in Figure 5 through 11 by plotting the dependent versus independent variable. In Figure 5 the averaged $\mathrm{H}_{\mathrm{g}}$ data is plotted versus gas pressure for a helium atmosphere at 283, 466, and $673 \mathrm{~K}$ for the ISM-II sample pair in light contact with a determined value of $D_{m p}=5.9 \mu \mathrm{m}$. The error bars represent the $3 \sigma_{R}$ uncertainty in the repeatability of measurement about each average value of $\mathrm{H}_{\mathrm{g}}$. The solid lines shown in Figure 5 serve to illustrate general trends and exhibit the dependence of $\mathrm{H}_{\mathrm{g}}$ on gas pressure. At $283 \mathrm{~K}$ an increase in $\mathrm{H}_{g}$ with increasing gas pressure between 0.1 and $0.8 \mathrm{MPa}$ is observed with $\mathrm{H}_{\mathrm{g}}$ decreasing thereafter with increasing pressure to $7 \mathrm{MPa}$. At $466 \mathrm{~K} \mathrm{H}_{\mathrm{g}}$ exhibits an increased dependence on gas pressure between 0.1 and $1 \mathrm{MPa}$ with a pronounced maximum in $\mathrm{H}_{\mathrm{g}}$ occurring at $1 \mathrm{MPa}$. At gas pressures above $1 \mathrm{MPa} \mathrm{H}_{\mathrm{g}}$ decreases in a manner similar to the observed behavior at $283 \mathrm{~K}$. At $673 \mathrm{~K} \mathrm{H}_{\mathrm{g}}$ again increases with increasing gas pressure up to $1 \mathrm{MPa}$ exhibiting a maximum at $1 \mathrm{MPa}$ and decreasing thereafter with increasing gas pressure.

It is noted that the $3 \sigma_{R}$ error bars increase with both increasing temperature and gas pressure with the largest uncertainty in repeatability of measurement occurring at $673 \mathrm{~K}$ and high gas pressures. 


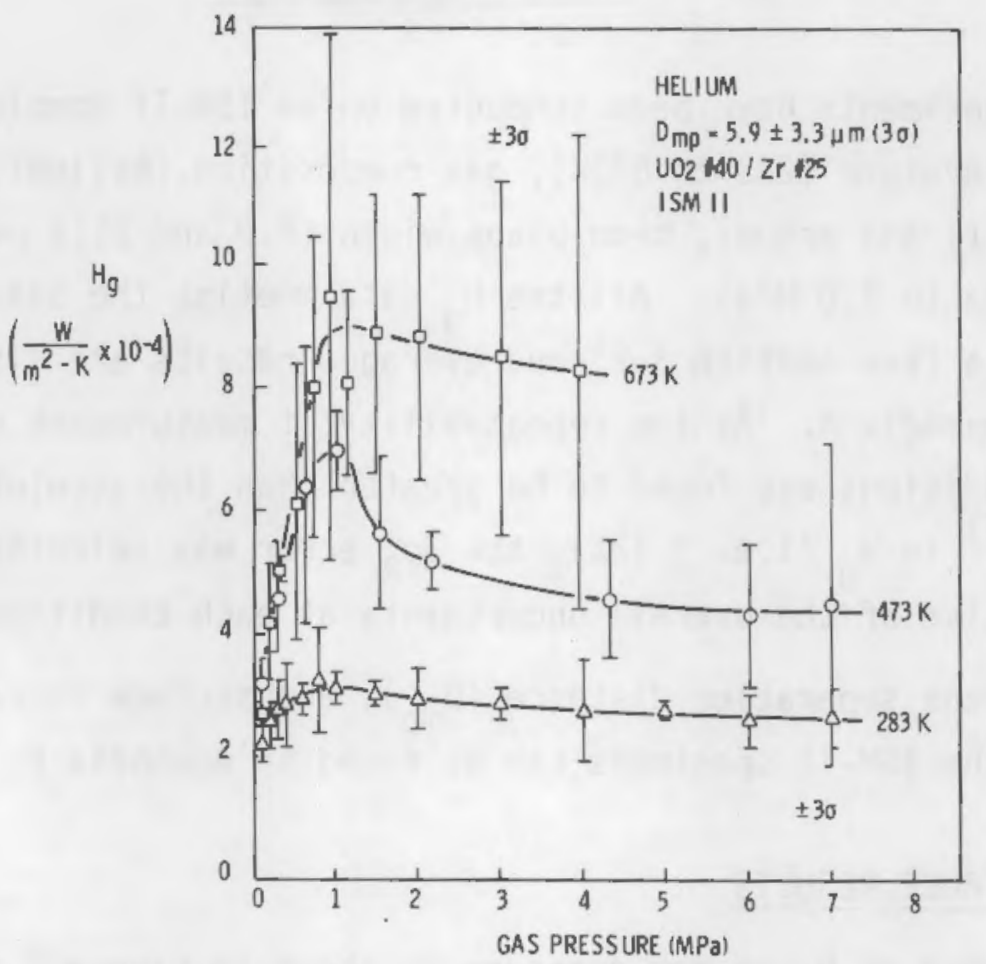

FIGURE 5. Hg Versus Gas Pressure for Helium Atmosphere ISM-II; Light Contact: $D_{m p}=5.9 \mu \mathrm{m}$

In Figure 6, the average $\mathrm{H}_{\mathrm{g}}$ data is plotted versus gas pressure for a He:Xe $(89.4: 10.6)$ atmosphere. The solid lines serve to illustrate the general trends in the results. $H_{g}$ increases with increasing gas pressure from 0.1 to $1 \mathrm{MPa}$ with dependence of $\mathrm{H}_{\mathrm{g}}$ on pressure being more pronounced at $473 \mathrm{~K}$ than at $287 \mathrm{~K}$. A maximum in $\mathrm{H}_{\mathrm{g}}$ is seen at approximately $1 \mathrm{MPa}$ with $\mathrm{H}_{\mathrm{g}}$ decreasing slightly with further increases in gas pressure to $6 \mathrm{MPa}$. A decrease in the absolute value of $\mathrm{H}_{\mathrm{g}}$ is also observed to occur upon increasing xenon content, as comparison of Figures 5 and 6 will show.

The effect of argon on $\mathrm{H}_{\mathrm{g}}$ is shown in Figures 7 and 8 for atmospheres of He:Ar (51.79:48:21) and argon (100), respectively. Although the observed dependence of $\mathrm{H}_{9}$ with gas pressure between 0.1 and $1 \mathrm{MPa}$ for $\mathrm{He}(100)$ and $\mathrm{He}: \mathrm{Xe}(89.4: 10.8)$ is similar to that observed in Figures 7 and 8 for He: $\operatorname{Ar}(51.79: 48.21)$ and $\operatorname{Ar}(100)$ (i.e. increasing $H_{g}$ over the range from 


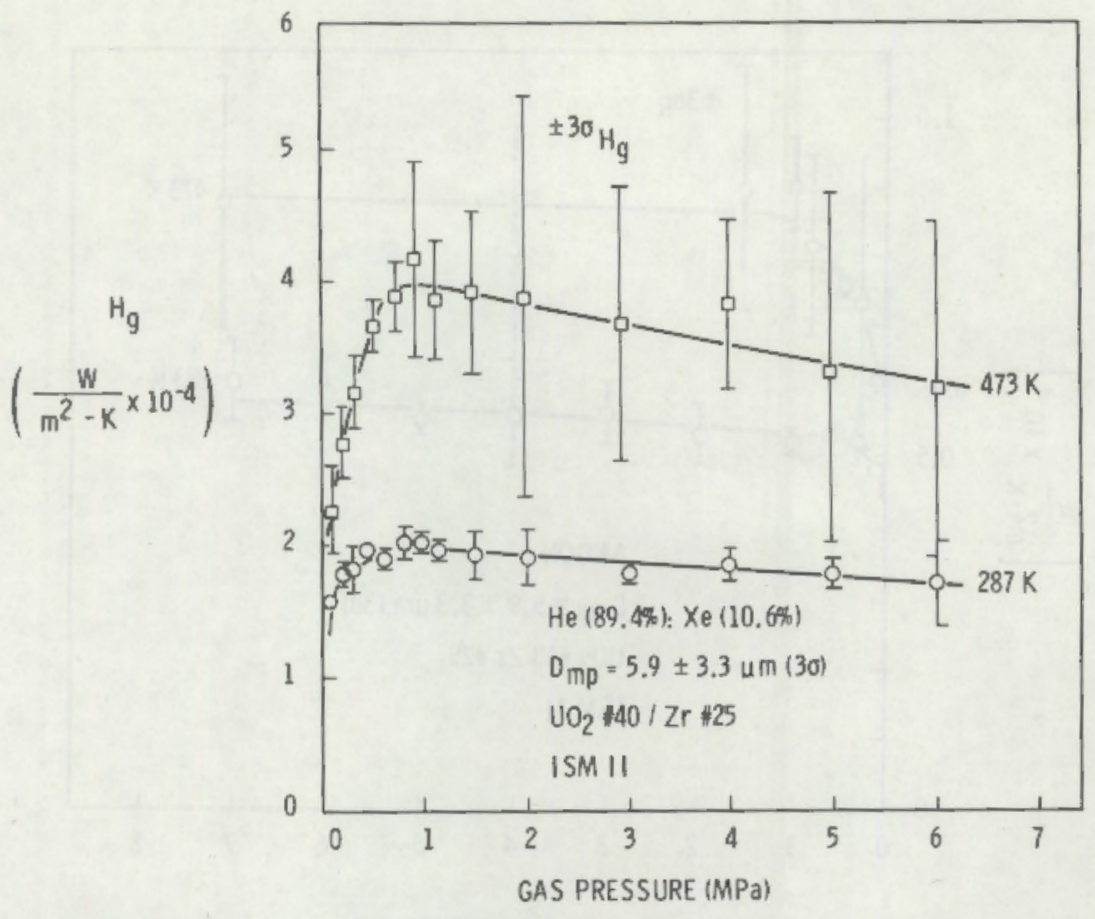

FIGURE 6. Hg Versus Gas Pressure for $\mathrm{He:Xe(89.4:10.6)}$ Atmosphere ISM-II; Light Contact: $\dot{O}_{\mathrm{mp}}=5.9 \mathrm{\mu m}$

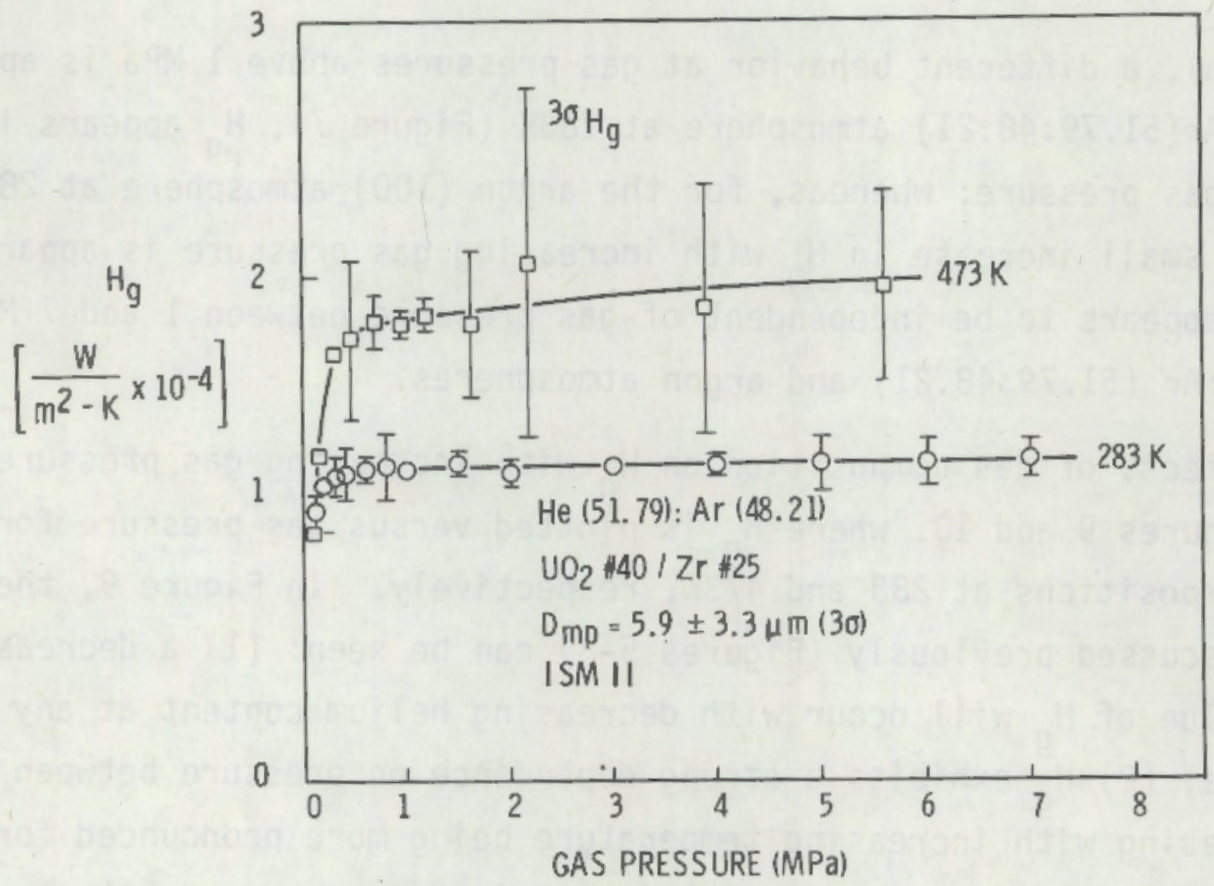

FIGURE 7. Hg Versus Gas Pressure for He:Ar(51.79:48.71) ISM-II; Light Contact: $0_{m p}=5.9 \mu \mathrm{m}$ 


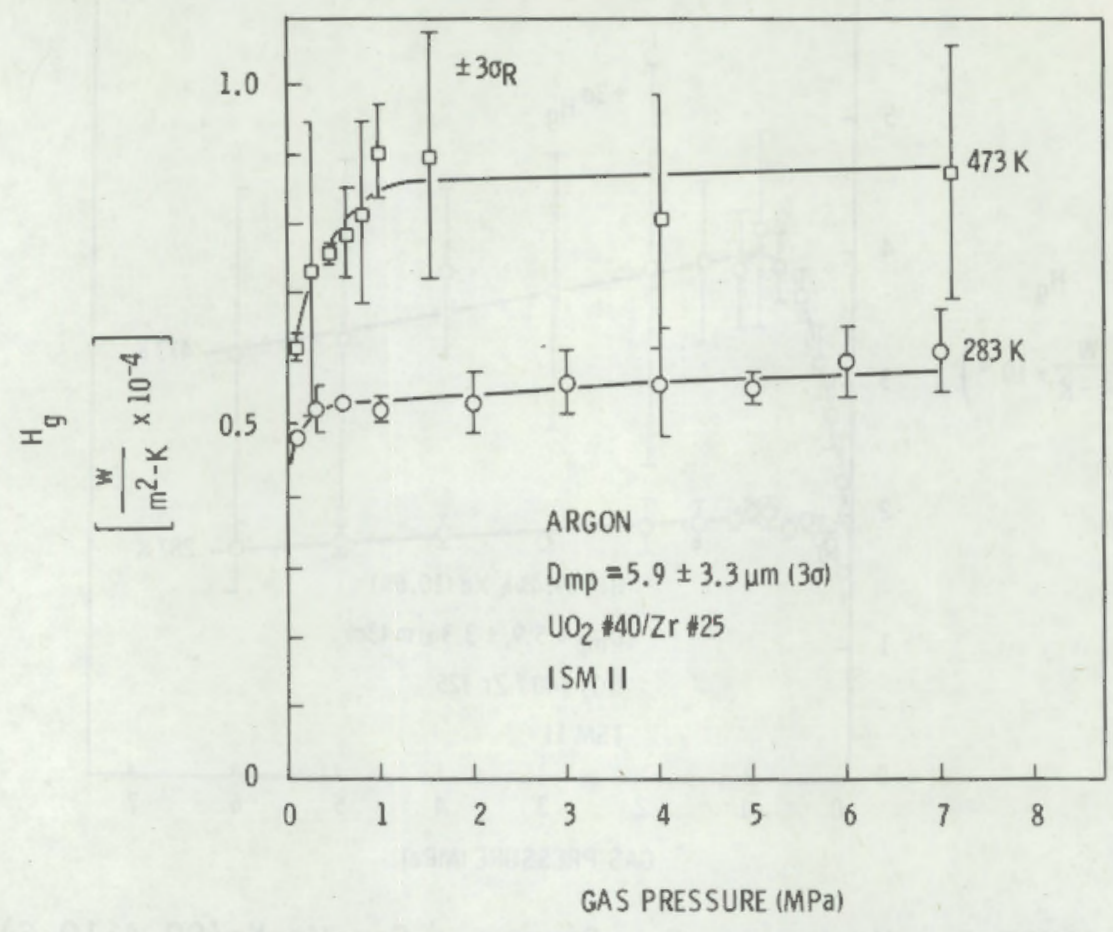

FIGURE 8. Hg Versus Gas Pressure for Argon Atmosphere ISM-II; Light Contact: $D_{m p}=5.9 \mu m$

0.1 to $1 \mathrm{MPa}$ ), a different behavior at gas pressures above $1 \mathrm{MPa}$ is apparent. For the $\mathrm{He}: \operatorname{Ar}(51.79: 48.21)$ atmosphere at 283K (Figure 7), $\mathrm{H}_{\mathrm{g}}$ appears independent of gas pressure; whereas, for the argon (100) atmosphere at 283K (Figure 8) very small increase in $\mathrm{H}_{\mathrm{g}}$ with increasing gas pressure is apparent. At $473 \mathrm{~K} \mathrm{H}$ appears to be independent of gas pressure between 1 and $7 \mathrm{MPa}$ for both the He:Ar (51.79:48.21) and argon atmospheres.

The effects of gas composition on $\mathrm{H}_{\mathrm{g}}$ with increasing gas pressure is shown in Figures 9 and 10 , where $\mathrm{H}_{\mathrm{g}}$ is plotted versus gas pressure for various gas compositions at 283 and $473 \mathrm{~K}$, respectively. In Figure 9 , the general features discussed previously (Figures 5-8) can be seen: (1) a decrease in the absolute value of $\mathrm{H}_{\mathrm{g}}$ will occur with decreasing helium content at any given gas pressure; (2) $\mathrm{H}_{\mathrm{g}}$ exhibits a strong dependence on pressure between 0.1 and $1 \mathrm{MPa}$ increasing with increasing temperature being more pronounced for helium than for argon; (3) $\mathrm{H}_{\mathrm{g}}$ decreases with increasing gas pressure between 1 and 


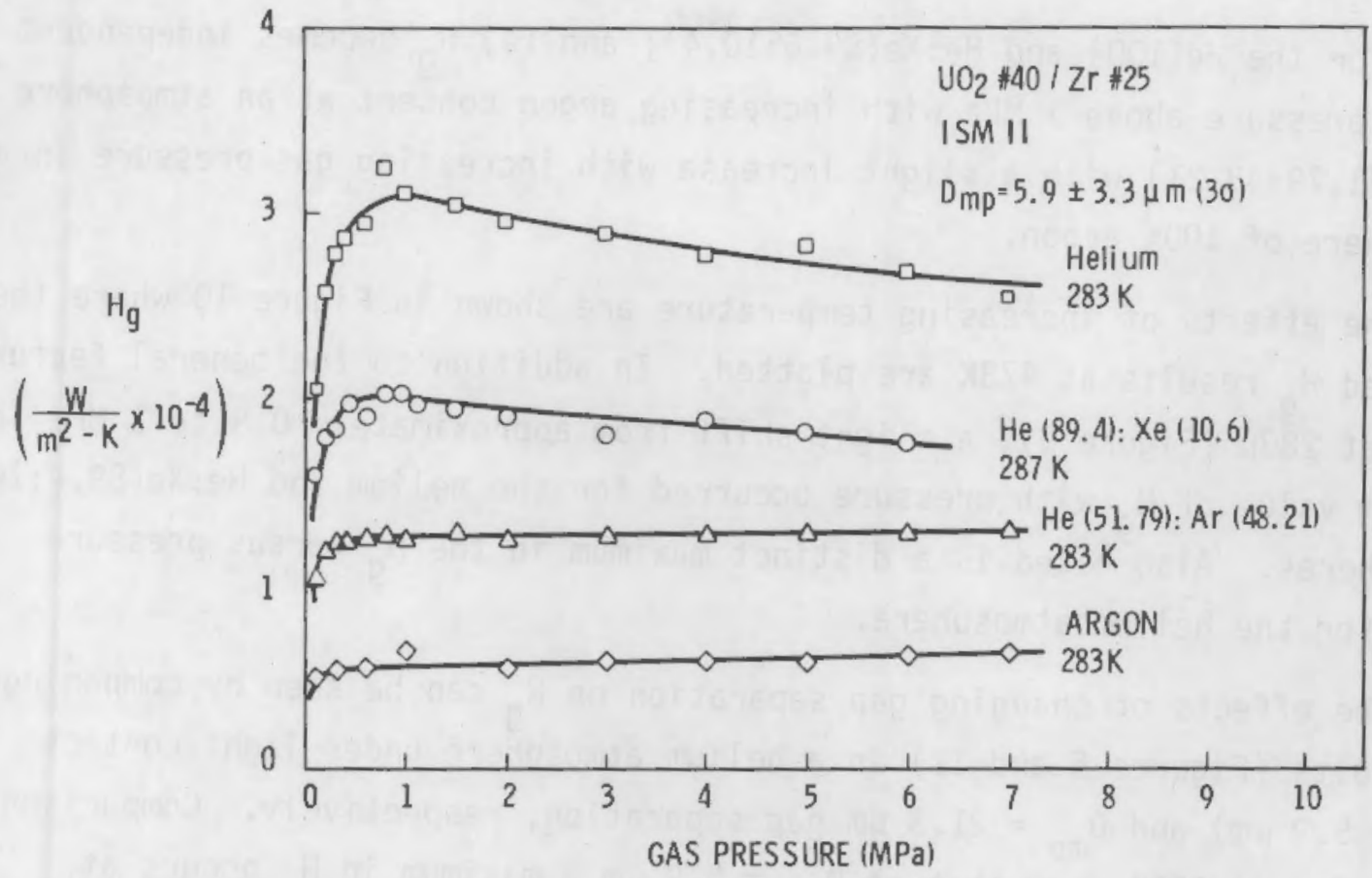

FIGURE 9. Hg Versus Gas Pressure for He: Xe(89.4:10.6), He: $\operatorname{Ar}(51.79: 48.21)$ and $\operatorname{Ar}(100)$ Atmosphere at 283K, ISM-II; Light Contact: $D_{m p}=5.9 \mu \mathrm{m}$

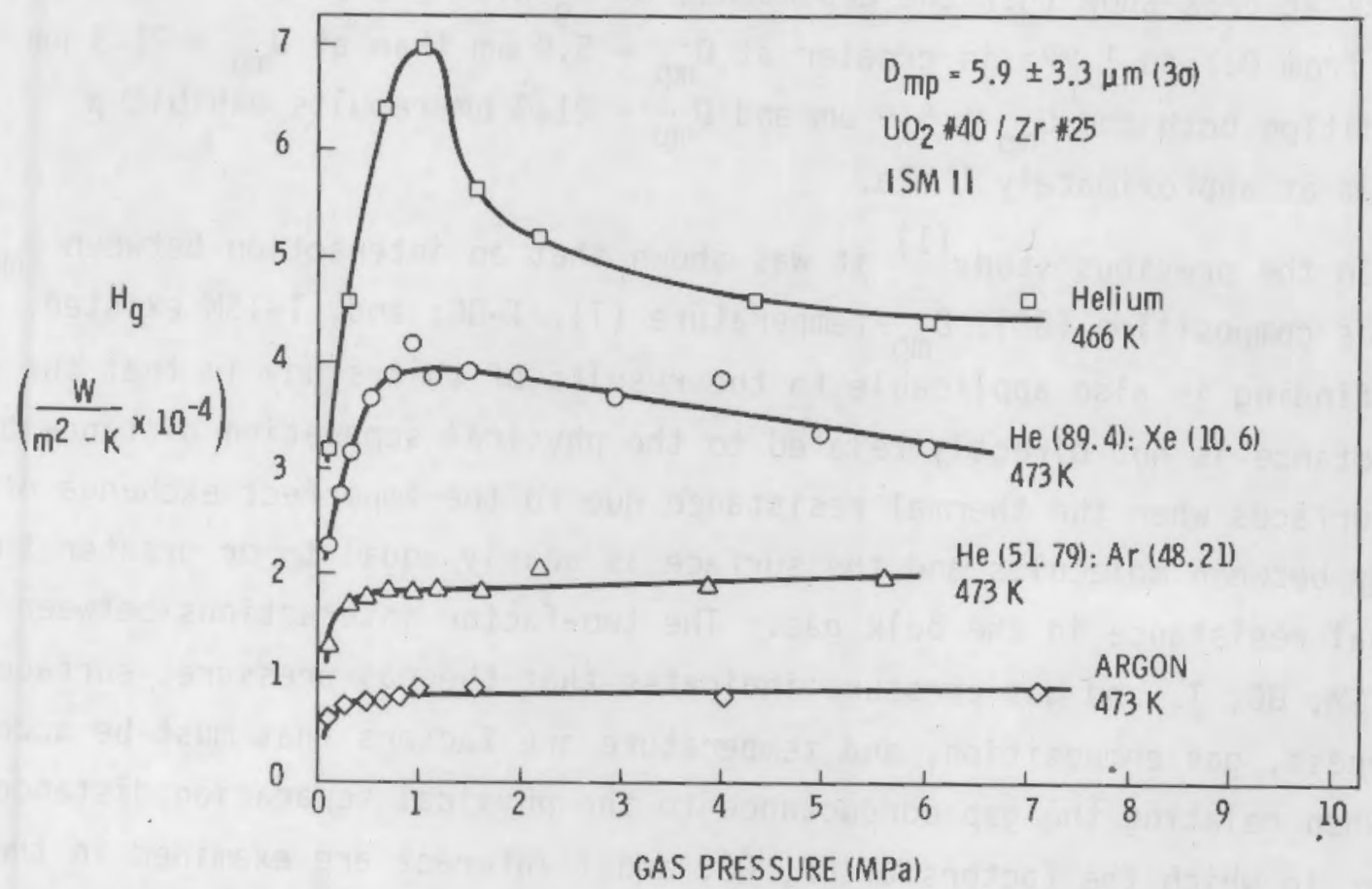

FIGURE 10. Hg Versus Gas Pressure for $\mathrm{He}(100)$, He:Xe(89.4:10.6), He: $X e(51.79: 48.21)$ and $\mathrm{Ar}(100)$ Atmospheres at $473 \mathrm{~K}$, ISM-II; Light Contact: $D_{\text {mp }}=5.9 \mu \mathrm{m}$ 
$7 \mathrm{MPa}$ for the $\mathrm{He}(100)$ and $\mathrm{He}: \mathrm{Xe}(89.6: 10.4)$; and (4) $\mathrm{H}_{\mathrm{g}}$ becomes independent of gas pressure above $1 \mathrm{MPa}$ with increasing argon content at an atmosphere of He:Ar(51.79:48.21) with a slight increase with increasing gas pressure in an atmosphere of $100 \%$ argon.

The effects of increasing temperature are shown in Figure 10 where the combined $\mathrm{H}_{\mathrm{g}}$ results at $473 \mathrm{~K}$ are plotted. In addition to the general features noted at $283 \mathrm{~K}$ (Figure 9), a slight shift from approximately 0.8 to $1 \mathrm{MPa}$ in the maximum value of $\mathrm{H}_{\mathrm{g}}$ with pressure occurred for the helium and $\mathrm{He}: \mathrm{Xe}(89.4: 10.4)$ atmospheres. Also noted is a distinct maximum in the $\mathrm{H}_{\mathrm{g}}$ versus pressure curve for the helium atmosphere.

The effects of changing gap separation on $\mathrm{H}_{\mathrm{g}}$ can be seen by comparing $H_{f}$ results (Figures 5 and 11 ) in a helium atmosphere under light contact $\left(D_{\mathrm{mp}}=5.9 \mu \mathrm{m}\right)$ and $D_{\mathrm{mp}}=21.3 \mu \mathrm{m}$ gap separation, respectively. Comparison of results at $283 \mathrm{~K}$ show that at $\mathrm{D}_{\mathrm{mp}}=5.9 \mu \mathrm{m}$ a maximum in $\mathrm{H}_{\mathrm{g}}$ occurs at $1 \mathrm{MPa}$ and exhibits a slight decrease with increasing gas pressure to $7 \mathrm{MPa}$. At. $D_{m p}=21.3 \mu m$, however, no maximum in $H_{g}$ is seen, and $H_{g}$ exhibits an increase with increasing gas pressure between 0.1 and $7 \mathrm{MPa}$. Comparison to results at $673 \mathrm{~K}$ show that the dependence of $\mathrm{H}_{\mathrm{g}}$ with gas pressure over the range from 0.1 to $1 \mathrm{MPa}$ is greater at $D_{\mathrm{mp}}=5.9 \mu \mathrm{m}$ than at $D_{\mathrm{mp}}=21.3 \mu \mathrm{m}$. In addition both the $D_{m p}=5.9 \mu m$ and $D_{m p}=21.3 \mu \mathrm{m}$ results exhibit a maximum at approximately 1. MPa.

In the previous studv ${ }^{(1)}$ it was shown that an interaction between $D_{\text {mip }}$-ISM, $D_{m p}$-gas composition (GC), $D_{m p}$-temperature (T), T-GC; and, T-ISM existed. This finding is also applicable to the results of this study in that the gap conductance is not directly related to the physical separation distance between two surfaces when the thermal resistance due to the imperfect exchange of energy between molecules and the surface is nearly equal to or greater than the thermal resistance in the bulk gas. The two-factor interactions between $0_{m p}$ and ISM, GC, T, and gas pressure indicates that the gas pressure, surface roughness, gas composition, and temperature are factors that must be accounted for when relating the gap conductance to the physical separation distance. The manner in which the factors of GP, GC, and T interact are examined in the next section. 


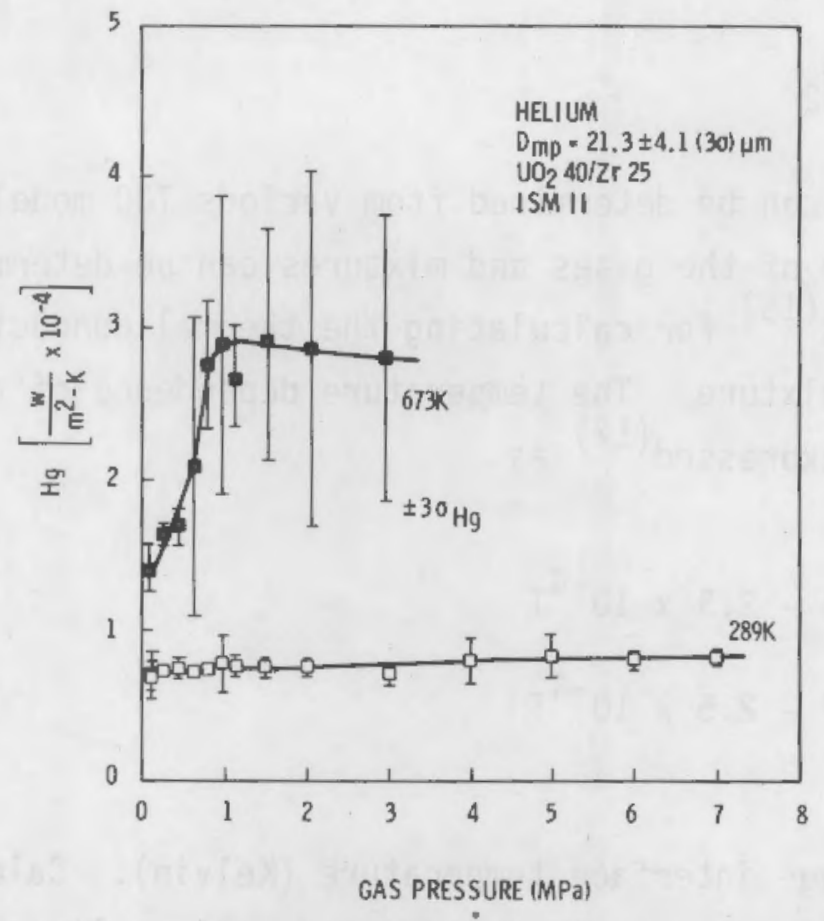

FIGURE 11. Hg Versus Gas Pressure for Helium Atmosphere ISM-II; $D_{m p}=21.3 \mu \mathrm{m}$

\subsection{COMPARISON OF $\mathrm{H}_{9}$ TO THE IDEAL GAP CONDUCTANCE EXPRESSION}

The dependence of $\mathrm{H}_{\mathrm{g}}$ on temperature, gas composition, gap width, and gas pressure can be calculated from the relationship

$$
H_{g}=\frac{K_{g a s}}{D_{m p}+g_{1}+g_{2}}
$$

where $D_{m p}$ is substituted for the "ideal" separation distance and $g_{1}$ and $g_{2}$ the respective TJD at the $\mathrm{DUO}_{2}$ and $\mathrm{Zr} 4$ surfaces. The temperatures used in calculating Equation 7 are taken as the mean temperature of the experiment since the MPD technique involves transient temperature measurement where $\Delta T$ is no more than a few degrees Kelvin (Section 3.2). If the accomodation coefficients at the $\mathrm{OUO}_{2}$ and $\mathrm{Zr} 4$ surfaces are considered to be equivalent, Equation 7 may be approximated as 


$$
H_{g} \approx K_{g a s} /\left(D_{m p}+2 g\right)
$$

where $g=g_{1}=g_{2}$

The quantity $\mathrm{g}$ can be determined from various TJD models (Table 1). The thermal conductivity of the gases and mixtures can be determined from the MATPRO relationships $(16)$ for calculating the thermal conductivity of a nonatomic gas and gas mixture. The temperature dependence of the accommodation coefficient can be expressed ${ }^{(17)}$ as

$$
\begin{aligned}
& { }^{a_{H e}}=0.425-2.3 \times 10^{-4} \mathrm{~T} \\
& { }^{a_{X e}}=0.749-2.5 \times 10^{-4} \mathrm{~T}
\end{aligned}
$$

where $T$ is the average interface temperature (Kelvin). Calculation of a and $a_{i}$ for other gases (i.e., argon) are computed using a linear extrapolation hetween $\mathrm{a}_{\mathrm{He}}$ and $\mathrm{a}_{\mathrm{Xe}}$ based on molecular weight. The effective molecular weight of the gas mixture is:

$$
\sum_{i} f_{i} M_{i}
$$

where $f_{i}$ is the mole fraction of species $i$. Justification for this procedure is given in Reference 18.

Equation 8 predicts that an increase in $\mathrm{H}_{\mathrm{g}}$ will occur with increasing gas pressure as a result of proportionate decrease in the TJD. At sufficiently high gas pressures when $2 \mathrm{~g} \ll \mathrm{D}_{\mathrm{mp}}$, Equation 8 predicts that the gas conductance will be independent of gas pressure insofar as $K_{\text {gas }}$ is dependent on gas pressure alone. The reader should note that the MATPRO relationships ${ }^{(1,16)}$ for predicting the thermal conductivity of a gas or gas mixture do not, at this time, contain any term that takes into account the pressure dependence of the gas thermal conductivity. 
Using the expression derived by Kennard for the temperature jump distance and Equation 8, the gap conductance was computed as a function of gas pressure for both helium and argon atmospheres. Comparison of Equation 8 to $\mathrm{H}_{\mathrm{g}}$ is made in Figures 12 to 14 for helium $\left(D_{m p}=5.9 \mu \mathrm{m}\right)$, argon $\left(D_{m p}=5.9 \mu \mathrm{m}\right)$, and helium $\left(D_{\mathrm{mp}}=21.3 \mu \mathrm{m}\right.$ ) atmosphere, respectively. At $283 \mathrm{~K}$ (in Figures 12-14) agreement between Equation 8 and $\mathrm{H}_{\mathrm{g}}$ is seen only for helium $\left(D_{\mathrm{mp}}=5.9 \mu \mathrm{m}\right)$ at pressures above $3 \mathrm{MPa}$ (Figure 12) and for helium $\left(D_{\mathrm{mp}}=21.3 \mu \mathrm{m}\right)$ between 1 and $7 \mathrm{MPa}$ (Figure 14). At temperatures above 283K no agreement between Equation 8 and $\mathrm{H}_{\mathrm{g}}$ is obtained. At 283K the $\mathrm{H}_{\mathrm{g}}$ results, above $1 \mathrm{MPa}$ for argon (Figure 13) and helium (Figure 14), show an increase of approximately $15 \%$ and $5 \%$, respectively, between 1 and $7 \mathrm{MPa}$. This is in accordance with the reported $(23,24)$ increase in the thermal conductivity of argon (12\%) and helium (2\%) over similar ranges of pressure. It again should be noted that the MATPRO relationships for the thermal conductivity of a gas and gas mixture do not account for an increase in the thermal conductivity of the gas with increasing gas pressure.

The difference between the $\mathrm{H}_{\mathrm{g}}$ results and the predicted gap conductance, as seen in Figures 12 to 14 especially across the range of pressures from 0.1 to $2 \mathrm{MPa}$, may be as a result of the following:

- The possibility of an indeterminate error influencing the $\mathrm{H}_{\mathrm{g}}$ results is not precluded. Gaseous convection may be a factor influencing the test results insofar as the $3 \sigma_{R}$ uncertainty was found to increase with both increasing gas pressure and temperature. However, if only the results at $283 \mathrm{~K}$ are considered, the general features (as described in Section 4) are still observed although not as pronounced as at the elevated temperatures. The presence of a hump in the $H_{g}$ versus pressure results is similar to results reported by Ho and Leidenfrost ${ }^{(24)}$ on the thermal conductivity of helium gas versus pressure. In this study "an unusual behavior" was observed for the pressure dependence of the thermal conductivity of helium below $2 \mathrm{MPa}$. The thermal conductivity data of Ho and Leidenfrost (shown in Figure 15) are similar to the dependence of $\mathrm{H}_{\mathrm{g}}$ on pressure insofar as an apparent enhanced conductance/conductivity is observed over similar pressure ranges. The differences in magnitude between observed 


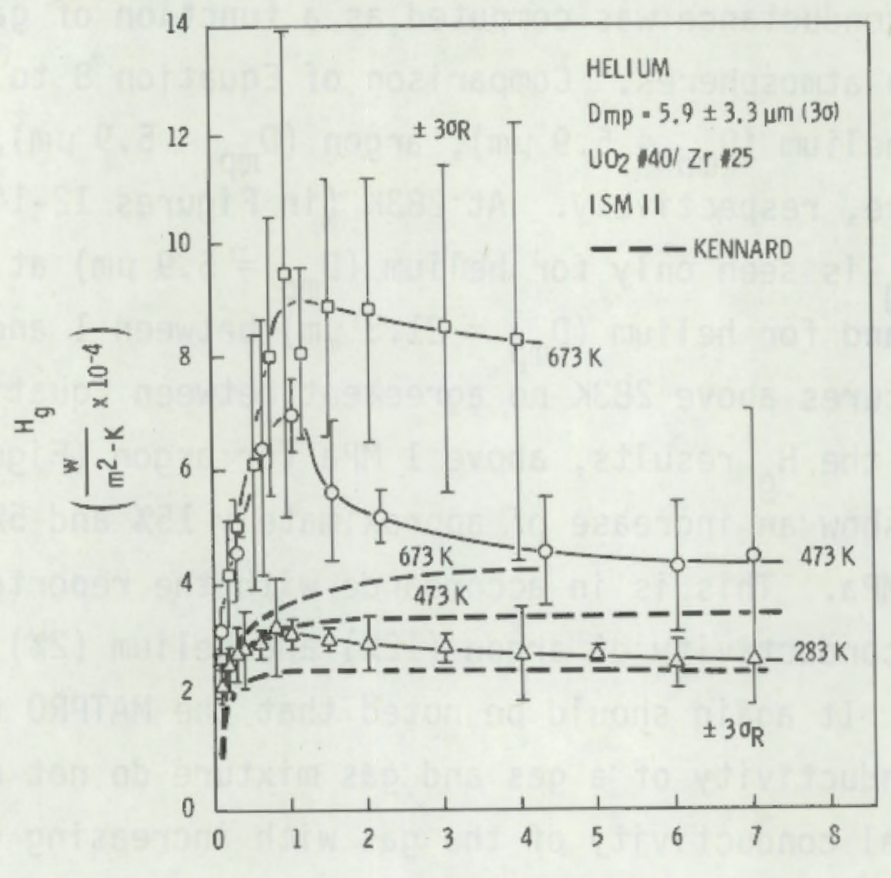

GAS PRESSURE (MPa)

FIGURE 12. $\mathrm{H}_{\mathrm{g}}$ Versus Gas Pressure for Helium Atmosphere Comparison of Results to Ideal Gap Conductance Expression (Equation 1) $D_{m p}=5.9 \mu \mathrm{m}$

$\mathrm{H}_{\mathrm{g}}$ (helium) and $\mathrm{K}_{\text {gas }}$ (helium) humps may result from the fundamental differences associated with the measurement techniques to ascertain the fine structure of conductance/conductivity versus pressure is concerned (i.e., MPD: a transient-time dependent technique versus the steady-state thermocouple technique employed by Ho and Leidenfrost).

- Given the behavior of $\mathrm{H}_{\mathrm{g}}$ to gas pressure and temperature shown in Figures 5-14, can the results be explained on the basis of existing theory of the temperature jump, i.e., Equation 9 ? Adjustment of $D_{m p}$ and/or the accommodation coefficient to various arbitrary values was found not to result in a combination of parameters consistent with the $\mathrm{H}_{\mathrm{g}}$ results. The $\mathrm{H}_{\mathrm{g}}$ results in Figures 5-14, however, appear consistent with conditions at an interface that include local areas of relative free molecular, transition, and continuum conductance. 
- The response of $\mathrm{H}_{\mathrm{g}}$ to changes in pressure will depend on the relative contributions of the various conductances to the overall gas conductance. This can be observed in Figures 12 and 13 by noting that the mean free path for argon gas molecules is approximately an order of magnitude less than for helium gas molecules at the same temperature and pressure. The behavior of $\mathrm{H}_{\mathrm{g}}$ with pressure for argon gas (Figure 13), appears consistent with the theory of the temperature jump. Whereas (in Figure 12) the theory of the temperature jump does not appear appropriate to explain the $\mathrm{H}_{\mathrm{g}}$ behavior with changes in the helium gas pressure.

- The presence of a hump in the $H_{g}$ versus pressure behavior for the $\mathrm{He}(100)$ and He: $\mathrm{Xe}(89.4: 10.6)$ atmospheres may result from the fact that the interface region consists of local areas where free molecular and/or transition conditions will be dominant as in the case of a helium atmosphere at lower

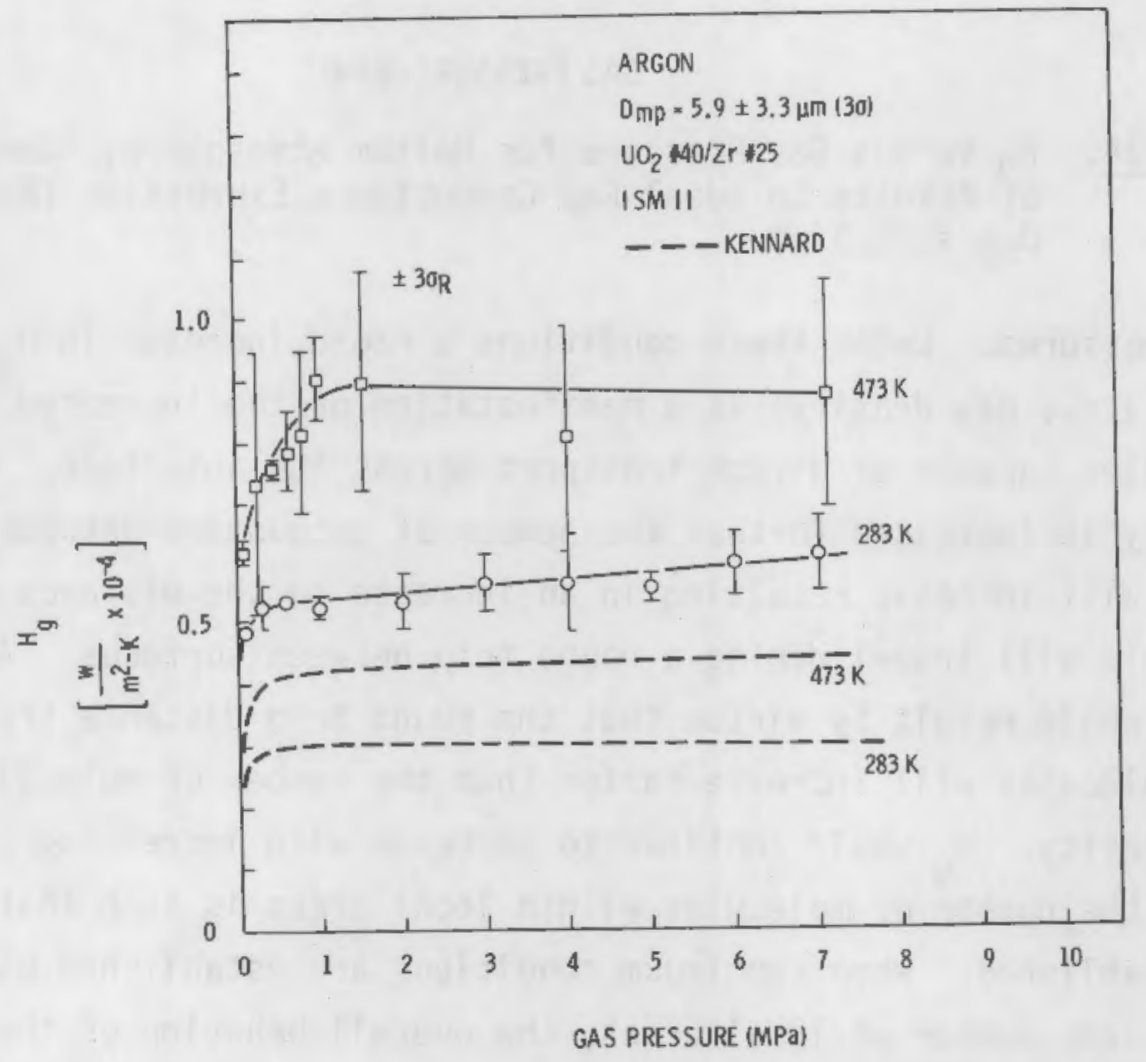

FIGURE 13. Hg Versus Gas Pressure for Argon Atmosphere. Comparison of Results to Ideal Gap Conductance Expression (Equation 1), $0_{\mathrm{mp}}=5.9 \mu \mathrm{m}$ 


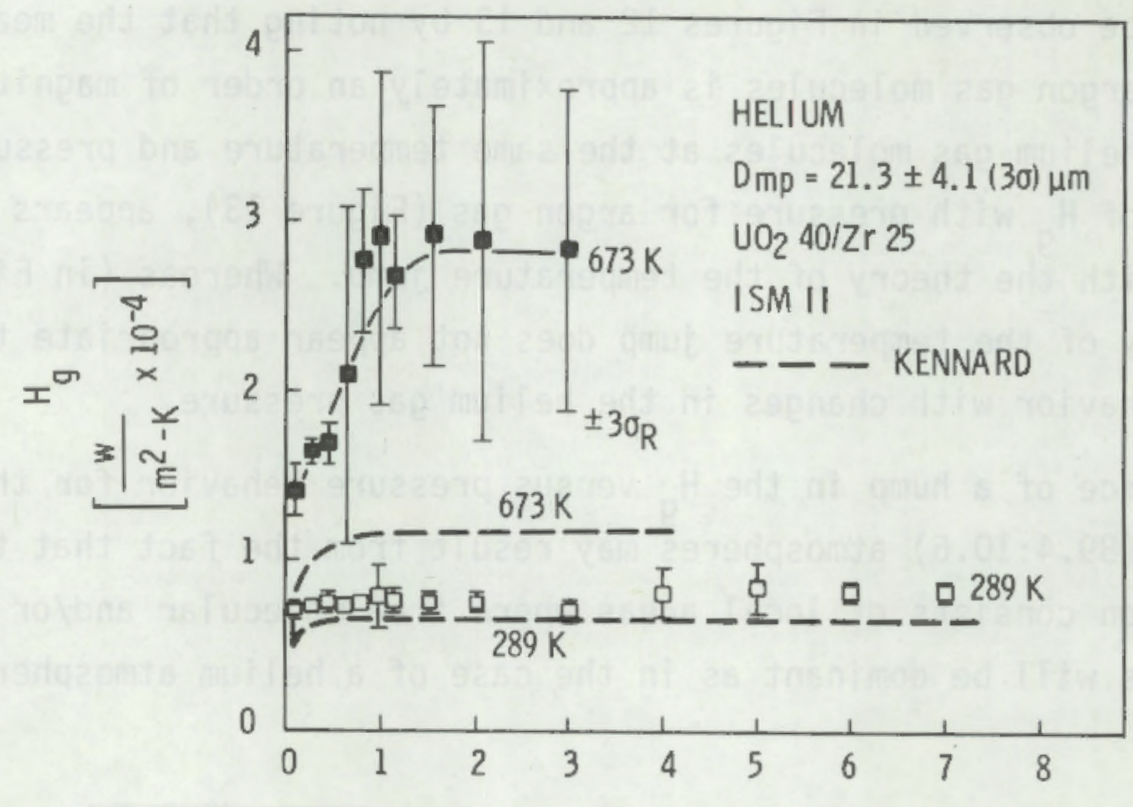

GAS PRESSURE (MPa)

FIGURE 14. Ho Versus Gas Pressure for Helium Atmosphere. Comparison of Results to Ideal. Gap Conductance Expression (Equation 2) $D_{m p}=21.3 \mu \mathrm{m}$

gas pressures. Under these conditions a rapid increase in $\mathrm{H}_{\mathrm{g}}$ with pressure (i.e., gas density) is a manifestation of the increased number of gas molecules capable of direct transport across the interface. As the gas density is increased further the number of encounters between gas molecules will increase resulting in an increase in the distance that a molecule will travel during a round trip between surfaces. A reduction in $\mathrm{H}_{\mathrm{g}}$ would result by virtue that the round trip distance traveled by the molecules will increase faster than the number of molecules, i.e., gas density. $\mathrm{H}_{\mathrm{g}}$ would continue to decrease with increasing gas density until the number of molecules within local areas is such that a continuum is established. When continuum conditions are established within a sufficient number of local areas, the overall behavior of the gap conductance can then be described as if a continuum were present in the interface. 
DATA BY: HOAND LEIDENFROST

PROG. IN HEAT AND MASS TRANSFER

VOL 1. 1969 PERGAMON PRESS INC.

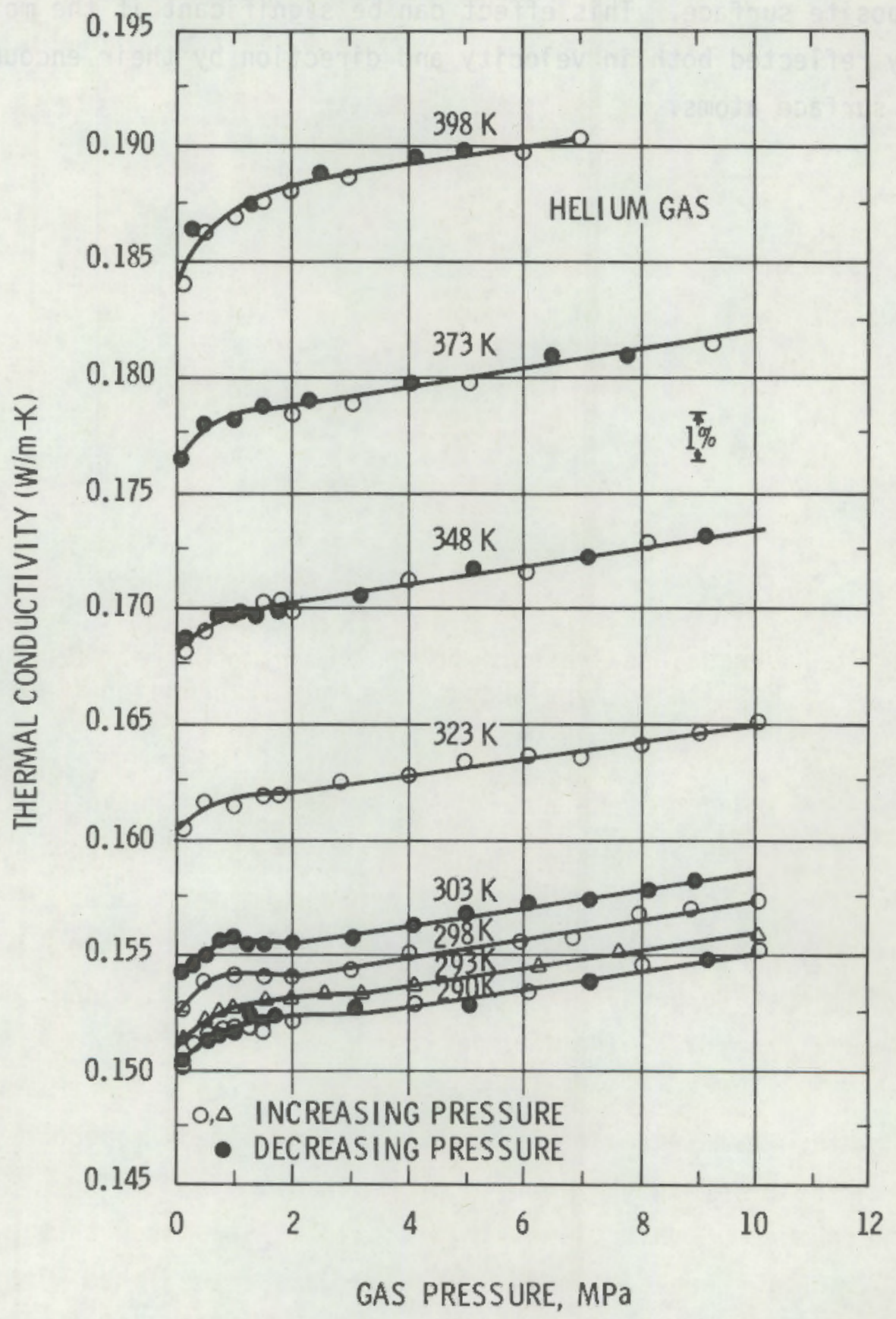

FIGURE 15. Thermal Conductivity of Helium Gas Yersus Pressure as Reported by Ho and Leidenfrost $(24)$ 
It is also necessary to appreciate that under free molecular conditions a redefinition of the physical meaning of the accommodation coefficient is necessary since a molecule incident upon a solid surface atom does so with the reflected energy it received during its encounter with the solid surface atoms at the opposite surface. This effect can be significant if the molecules are specularly reflected both in velocity and direction by their encounter with the solid surface atoms. 


\subsection{CONCLUSIONS AND RECOMMENDATIONS}

The gap conductance between a $\mathrm{DUO}_{2}$ and Zircalay-4 sample pair (ISM II) was measured under light contact $\left(D_{m p}=5.9 \mu \mathrm{m}\right)$ and small gap $\left(D_{m p}=21.3 \mu \mathrm{m}\right.$ or $0.9 \mathrm{mil}$ ) conditions using the MPD technique. The $\mathrm{H}_{\mathrm{g}}$ results show a dependence on gas pressure, gas composition, temperature, and gap separation.

The response of $\mathrm{H}_{\mathrm{g}}$ to changes in gas pressure, gas composition, and temperature is consistent from a perspective that the interface region between two surfaces in close proximity and/or contact consists of localized areas where the mechanisms of free molecular, transition, and continuum heat transfer occur. The response of $\mathrm{H}_{9}$ to changes in gas pressure, gas composition, temperature, gas separation, etc., therefore depends on the dominant heat transfer mechanism within the interface. This conclusion is supported by the observation that the response of $\mathrm{H}_{\mathrm{g}}$ to changes in the gas density (i.e., pressure) for the $\mathrm{He}(100)$ and $\mathrm{He}: \mathrm{Xe}(89.4: 10.6)$ atmospheres is different than for the He: $\operatorname{Ar}(51.79: 48.21)$ and $\operatorname{Ar}(100)$ atmospheres at the same interfacial gap conditions; and, that the mean free path length for argon molecules is approximately an order of magnitude less than the mean free path for helium molecules. Thus, the $H_{g}$ response to changes in pressure for a $\mathrm{He}: \operatorname{Ar}(51.79: 48.21)$ and $\operatorname{Ar}(100)$ atmosphere is what would be expected if transition to continuum conditions dominated the gap conductance; and, the $\mathrm{H}_{\mathrm{g}}$ results in the $\mathrm{He}(100)$ and He:Xe(89.4:10.6) atmosphere as if free-molecular to transition conditions alone dominated.

The study also concludes that the currently applied temperature jump formulas (developed to account for the imperfect energy transfer between molecules and the fuel and clad surfaces) are not theoretically appropriate for estimating the gap conductance under fuel/clad conditions when $K N>0.01$ and $\psi 20.1$. The reason for the inappropriateness arises from the assumption that only a continuum will be present. Clearly, when fuel/clad gap closure occurs, local areas of free molecular, transition, and continuum conductance are all present. In the local areas where free molecular and transition conditions are present, Fourier's law of heat conduction is not valid. As the proportion of freemolecular/transition conductance increases with fuel/clad gap closure, 
estimation of the gap conductance using the ideal gap conductance expression becomes questionable. However, the study concludes, as in the previous report, ${ }^{(1)}$ that the ideal gap conductance expression, as currently used in fuel performance codes such as GAPCON THERMAL III, (8) underestimates the gap conductance.

The underestimation of the gap conductance is assumed to result from failure to account for an enhanced conduction which arises from a reduction in the number of molecular encounters within local areas where free-molecular transition conditions are prevalent. This conclusion is supported by the observation that $\mathrm{H}_{\mathrm{g}}$ exhibits a hump at a pressure of approximately $1 \mathrm{MPa}$ for the $\mathrm{He}(100)$ and $\mathrm{He}: \mathrm{Xe}(89.4: 10.6)$ atmospheres. This observation is similar to a reported (24) "unusual behavior" for the thermal conductivity of helium versus pressure between 1 and $2 \mathrm{MPa}$. The presence of an enhanced gap conductance due to a reduction in the number of molecular encounters appears plausible if consideration is given to the nature of the velocity of gas molecules in time and space.

On the basis of the results obtained in this study (a) the following areas of additional research are recommended:

- Definition of typical fuel:clad surface morphologies with respect to the relative free molecular, transition, and continuum contributions to the overall gap conductance. A study of this kind would aid in modeling relative contributions of local areas of free molecular, transition and continuum conductance for various mating fuel/clad surface morphologies

- Theoretical treatment in time and space and experimental measurement of free molecular and transition heat transfer processes between two surfaces in close proximity is needed in order to redefine the physical meaning of the accommodation coefficient and the nature of the velocity distribution of gas molecules.

(a) The reader is referred to the previous report (1) for additional recormended areas of study. 


\subsection{REFERENCES}

1. Garnier, J. E. and S. Begej, Ex-Reactor Determination of Thermal Gap and Contact Conductance Between Uranium Dioxide:Zircaloy-4 Interfaces. Stage I: Low Gas Pressure. NUREG/CR-0330, PNL-2696; Pac if ic Northwest Laboratory, Apri1 1979. **

2. Williford, R. E. and C. R. Hann, Effects of Fill Gas Composition and Pellet Eccentricity. Battelle-2285, Pacific Northwest Laboratories, July 1977. $\star \bar{k}$

3. Cunningham, M. E., R. E. Williford, and C. R. Hann, Effects of Fill Gas Composition and Pellet Eccentricity: Comparison Between Instrumented Fuel Assemblies IFA-431 and IFA-432. NUREG/CR-0331, PNL-2729, Pac ific Northwest Laboratory, April 1979.*

4. Lanning, D. D. and M. E. Cunn ingham, Startup Data Report for NRC/PNL Halden Assembly IFA-513, NUREG/CR-0862, PNL-2948, Pacif ic Northwest Laboratory, July 1979. *

5. Kennard, E. H., Kinetic Theory of Gases. McGraw-Hill, New York, NY, 1938.

6. Lloyd, W. R., D. P. Wilkins, and P. R. Hi11, "Heat Transfer in MultiComponent Nonatomic Gases in the Low, Intermediate, and High Pressure Regime." Nuclear Thermionics Conference, 1973.

7. Beyer, C. E., C. R. Hann, D. D. Lanning, F. E. Panisko, and L. J. Parchen, GAPCON-THERMAL-II: A Computer Program for Calculating the Thermal Behavior of an Oxide Fuel Rod. Battelle-1898, Pacific Northwest Laboratories, 1975. *ᄎ

8. GAPCON-THERMAL-3: Code Description. PNL-2434, Pac ific Northwest Laboratory, January 1978.

9. Roberts, J. T. A. et al., Planning Support Document for the EPRI LWR Fuel Performance Program EPRI-NP-737, Electric Power Research Institute, pp. 48-52, 1978.

10. Berna, G.A., Bohn, M. P., and Coleman, D. R., FRAPCON-1: A Computer Code for the Steady State Analysis of Oxide Fuel Rods. CDAP-TR-78-032-R1, November 1978.

11. Wordsworth, J., "IAMBUS-1--A Digital Computer Code for the Design, In-Pile Performance Prediction and Postirradiation Analysis of Arbitrary Fuel Rods." Nuclear Science and Engineering 31:309, 1974.

12. Knudsen, M., "Kinetic Theory of Gases," Methuen's Monographs on Physical Subjects. Methuen and Co. Ltd., London, 2nd ed., 1933. See also, Ann. Physik, 34, 593 (1911). 
13. Loyalka, S. K., "Gap Conductance in Reactor Fuel Elements," LWR Heat Transfer and Fluid Flow Notes. Trans. ANS., p. 466, June 1977.

14. Maxwe11, J. C., Phil. Trans. Roy. Soc. 170:332-on, 1879.

15. Surface Texture, American Standards, AA 846.1, 1962.

16. Reymann, G. et al., MATPRO-10: A Handbook of Materials Properties for Use in the Analysis of LWR Fuel Rod Behavior, Appendix C. TREE-NUREG-1180, February 1978. ${ }^{* *}$

17. Ullman, A., R. Acharya, and D. R. Olander, "Thermal Accommodation Coefficients of Inert Gases on Stainless Steel and $\mathrm{UO}_{2} . " \mathrm{~J}$. Nucl. Materials 51:277, 1974.

18. Lanning, D. D. and C. R. Hann, Review of Methods Applicable to the Calculation of Gap Conductance in Zircaloy-Clad $\mathrm{UO}_{2}$ Fuel Rods. Battelle-1894, Pacific Northwest Laboratories, Apri1 1975.

19. Goodman, F. 0., J. Phys. Chem. Solids 26 (1965) p. 85.

20. Nocilla, S and M. G. Chiado-Piat, "Studies on the Behavior of Gas Molecules Scattered by a Solid Surface." Rarefield Gas Dynamics Vol. II, Proceedings of 6 th Symposium, ed. by L. Trilling and H. Y. Wackman, Academic Press, NY, 1969.

21. Loyalka, S. K., Quarterly Progress Report Covering Period from 1-1-79 to 3-30-79, U.S. Nuclear Regulatory Commission Contract No. NRC-04-78-201. Nuclear Engineering Dept., University of Missouri-Columbia, Columbia, MO 65201.

22. Parker, W. J., R. J. Jenkins, C. P. Butler, and G. L. Abbott, "Flash Method of Determining Thermal Diffusivity, Heat Capacity and Therma 1 Conductivity." J. Appl. Phys. 32(9):1679, 1961.

23. Hanley, H. J. M., R. D. McCarty, and W. M. Haynes "The Viscosity and Thermal Conductivity Coefficients for Dense Gaseous and Liquid Argon, Krypton, Xenon, Nitrogen, and Oxygen", J. Phys. Chem. Ref. Data $\underline{3}$ (4): $979,1974$.

24. Ho, C. Y., and W. Leidenfrost, "Precise Determination of the Thermal Conductivity of Helium Gas at High Pressures and Moderate Temperatures." Progress in Heat and Mass Transfer, Vol. 1, 55, Pergamon Press, 1969.

*Available for purchase from the NRC/GPO Sales Program, U.S. Nuclear Regulatory Commission, Washington, D.C. 20555, and the National

Technical Information Service, Springfield, VA 22161.

**Available for purchase from the National Technical Information Service, Springfield, VA 22161. 
APPENDIX A

MPD EXPERIMENTAL DATA 


\section{Contents:}

Pair Code: $\quad \mathrm{DUO}_{2}-40: \mathrm{Zr} 4-25$

ISM: II

Gas Compositions: He (100\%)

$\operatorname{Ar}(100 \%)$

He (51.79\%): $\operatorname{Ar}(48.21 \%)$

$\mathrm{He}(89.4 \%): \mathrm{Xe}(10.6 \%)$

Temperatures: $\quad 283,473,673 \mathrm{~K}$

$D_{\mathrm{mp}}$

$5.9 \pm 3.3 \mu \mathrm{m}(3 \sigma)$

$21.3 \pm 4.1 \mu \mathrm{m}(3 \sigma)$

The chronological order of data aquisition can be ascertained from the "Data I.D." symbol which consists of the magnetic tape cartridge letter and run number stored on a particular tape, e.9., A-1, A-2, -.---, B-1, B-2, -.--. 


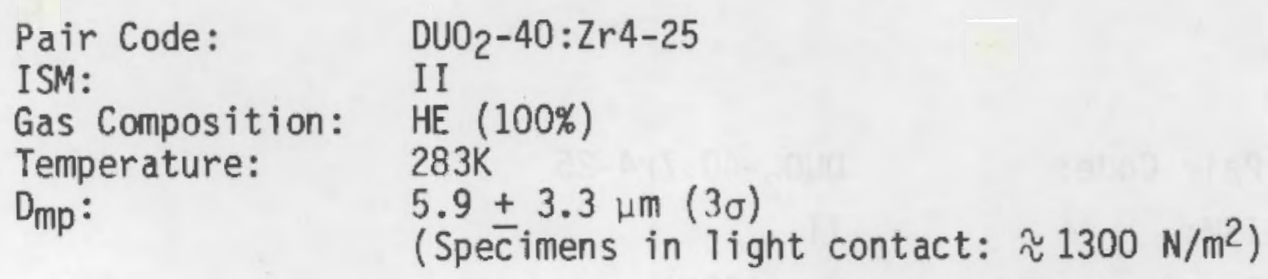

\begin{tabular}{|c|c|c|c|c|c|}
\hline $\begin{array}{c}\text { Gas } \\
\text { Pressure } \\
(\mathrm{MPa}) \\
\end{array}$ & $\begin{array}{l}\text { Data } \\
\text { I.D. * }\end{array}$ & $\left(w / m^{2}-K \times 10^{-4}\right)$ & $\begin{array}{l}\text { Avg } H_{g} \\
\left(\mathrm{w} / \mathrm{m}^{2}-\mathrm{K} \times 10^{-4}\right)\end{array}$ & $\begin{array}{c}{ }^{3 \sigma_{R}} \\
\left(w / m^{2}-K \times 10^{-4}\right) \\
\end{array}$ & $\begin{array}{l}3 \sigma_{R} \\
(\%)\end{array}$ \\
\hline 0.102 & $\begin{array}{l}A-1 \\
A-2 \\
A-3 \\
B-24 \\
D-25 \\
D-26 \\
F-33 \\
F-34 \\
F-35 \\
I-43 \\
I-44 \\
I-45 \\
I-46\end{array}$ & $\begin{array}{l}2.277 \\
2.255 \\
2.075 \\
2.212 \\
2.153 \\
2.107 \\
2.100 \\
2.161 \\
2.107 \\
1.929 \\
1.918 \\
1.943 \\
1.890\end{array}$ & 2.086 & 0.391 & 18.7 \\
\hline 0.20 & $\begin{array}{l}A-4 \\
A-5 \\
A-6\end{array}$ & $\begin{array}{l}2.615 \\
2.456 \\
2.633\end{array}$ & 2.568 & 0.292 & 11.4 \\
\hline 0.30 & $\begin{array}{l}A-7 \\
A-8 \\
A-9\end{array}$ & $\begin{array}{l}2.592 \\
2.866 \\
2.870\end{array}$ & 2.776 & 0.478 & 17.2 \\
\hline 0.40 & $\begin{array}{l}A-10 \\
A-11 \\
A-12 \\
B-23\end{array}$ & $\begin{array}{l}2.775 \\
2.697 \\
2.740 \\
3.221\end{array}$ & 2.858 & 0.732 & 25.6 \\
\hline 0.60 & $\begin{array}{l}A-13 \\
A-14 \\
A-15\end{array}$ & $\begin{array}{l}2.899 \\
2.896 \\
3.042\end{array}$ & 2.946 & 0.250 & 8.5 \\
\hline 0.80 & $\begin{array}{l}A-15 \\
A-17 \\
A-18\end{array}$ & $\begin{array}{l}2.451 \\
3.217 \\
3.546\end{array}$ & 3.238 & 0.894 & 27.5 \\
\hline 1.00 & $\begin{array}{l}A-10 \\
A-20 \\
A-21\end{array}$ & $\begin{array}{l}3.210 \\
3.039 \\
3.056\end{array}$ & 3.102 & 0.283 & 9.1 \\
\hline
\end{tabular}


Pair Code:

ISM:

Gas Composition:

Temperature:

$O_{\mathrm{mp}}$ :
$\mathrm{OU}_{2}-40: 2 r 4-25$

I I

HE $(100 \%)$

$283 \mathrm{~K}$

$5.9+3.3 \mu \mathrm{m}(3 \sigma)$

(Specimens in light contact: $\approx 1300 \mathrm{~N} / \mathrm{m}^{2}$ )

\begin{tabular}{|c|c|c|c|c|c|}
\hline $\begin{array}{l}\text { Gas } \\
\text { Pressure } \\
(\mathrm{MPa}) \\
\end{array}$ & $\begin{array}{l}\text { Oata } \\
\text { I.D.* }\end{array}$ & $\left(w / m^{2}-K \times 10^{-4}\right)$ & $\begin{array}{c}\text { Avg } H_{g} \\
\left(w / m^{2}-K \times 10^{-4}\right)\end{array}$ & $\begin{array}{c}{ }^{3 \sigma_{R}} \\
\left(w / m^{2}-k \times 10^{-t}\right) \\
\end{array}$ & $\begin{array}{l}3 \sigma_{R} \\
(\%)\end{array}$ \\
\hline 1.50 & $\begin{array}{l}A-22 \\
B-1 \\
B-2\end{array}$ & $\begin{array}{l}2.997 \\
3.165 \\
3.077\end{array}$ & 3.080 & 0.252 & 8.2 \\
\hline 2.00 & $\begin{array}{l}B-3 \\
B-4 \\
B-5\end{array}$ & $\begin{array}{l}2.796 \\
3.104 \\
3.089\end{array}$ & 2.996 & 0.521 & 17.4 \\
\hline 3.00 & $\begin{array}{l}B-6 \\
B-7 \\
B-8 \\
B-22\end{array}$ & $\begin{array}{l}2.825 \\
2-920 \\
2.801 \\
2.965\end{array}$ & 2.878 & 0.232 & 8.1 \\
\hline 4.00 & $\begin{array}{l}B-9 \\
B-10 \\
B-11\end{array}$ & $\begin{array}{l}2.637 \\
2.558 \\
3.079\end{array}$ & 2.758 & 0.842 & 30.5 \\
\hline 5.00 & $\begin{array}{l}B-12 \\
B-13 \\
B-14\end{array}$ & $\begin{array}{l}2.739 \\
2.823 \\
2.843\end{array}$ & 2.802 & 0.166 & 5.9 \\
\hline 6.00 & $\begin{array}{l}B-15 \\
B-16 \\
B-17\end{array}$ & $\begin{array}{l}2.821 \\
2.575 \\
2.590\end{array}$ & 2.562 & 0.414 & 15.6 \\
\hline 7.00 & $\begin{array}{l}B-18 \\
B-19 \\
B-20 \\
B-21 \\
F-1 \\
F-2 \\
F-3\end{array}$ & $\begin{array}{l}2.942 \\
2.608 \\
2.766 \\
2.583 \\
2.358 \\
2.367 \\
2.278\end{array}$ & 2.557 & 0.723 & 28.3 \\
\hline
\end{tabular}

* Data are listed in chronological order of aquisition according to file letter and run number, e.g., (A-1, A-2, A-3, ---, B-1, B-2, B-3,---). 


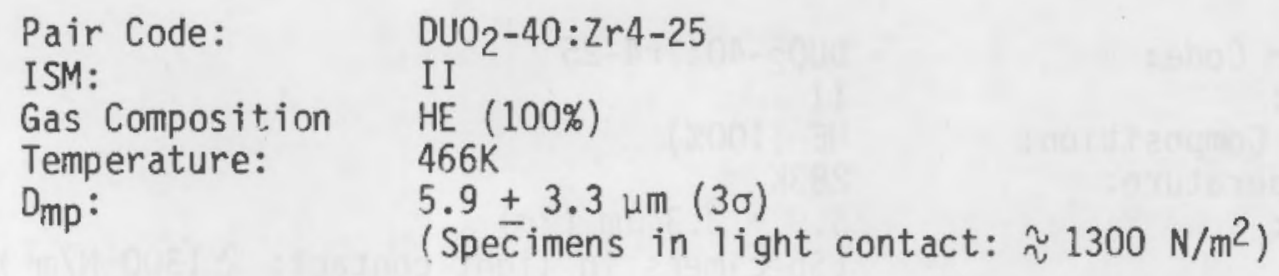

\begin{tabular}{|c|c|c|c|c|c|}
\hline $\begin{array}{c}\text { Gas } \\
\text { Pressure } \\
\text { (MPa) }\end{array}$ & $\begin{array}{l}\text { Data } \\
\text { I.D.* }\end{array}$ & $\left(w / m^{2}-K \times 10^{-4}\right)$ & $\begin{array}{l}\text { Avg } H_{g} \\
\left(w / m^{2}-K \times 10^{-4}\right)\end{array}$ & $\begin{array}{c}{ }^{3 \sigma_{R}} \\
\left(w / m^{2}-K \times 10^{-4}\right) \\
\end{array}$ & $\begin{array}{l}3 \sigma_{R} \\
(\%)\end{array}$ \\
\hline 0.102 & $\begin{array}{l}F-29 \\
F-30 \\
F-31\end{array}$ & $\begin{array}{l}3.186 \\
3.034 \\
3.329\end{array}$ & 3.183 & 0.443 & 13.9 \\
\hline 0.29 & $\begin{array}{l}F-26 \\
F-27 \\
F-28\end{array}$ & $\begin{array}{l}4.893 \\
4.311 \\
4.488\end{array}$ & 4.564 & 0.895 & 19.6 \\
\hline 0.65 & $\begin{array}{l}F-23 \\
F-24 \\
F-25\end{array}$ & $\begin{array}{l}5.580 \\
7.083 \\
6.453\end{array}$ & 6.372 & 2.264 & 35.5 \\
\hline 1.03 & $\begin{array}{l}F-20 \\
F-21 \\
F-22\end{array}$ & $\begin{array}{l}6.779 \\
6.902 \\
7.209\end{array}$ & 6.963 & 0.664 & 9.5 \\
\hline 1.55 & $\begin{array}{l}F-17 \\
F-18 \\
F-19\end{array}$ & $\begin{array}{l}5.122 \\
5.825 \\
5.905\end{array}$ & 5.617 & 1.292 & 23.0 \\
\hline 2.17 & $\begin{array}{l}F-14 \\
F-15 \\
F-16\end{array}$ & $\begin{array}{l}5.163 \\
5.348 \\
5.032\end{array}$ & 5.181 & 0.476 & 9.2 \\
\hline 4.33 & $\begin{array}{l}F-11 \\
F-12 \\
F-13\end{array}$ & $\begin{array}{l}4.556 \\
4.233 \\
4.911\end{array}$ & 4.567 & 1.017 & 22.2 \\
\hline 6.03 & $\begin{array}{l}F-8 \\
F-9 \\
F-10\end{array}$ & $\begin{array}{l}4.537 \\
4.866 \\
3.700\end{array}$ & 4.368 & 1.202 & 27.5 \\
\hline 7.00 & $\begin{array}{l}F-4 \\
F-5 \\
F-6 \\
F-7\end{array}$ & $\begin{array}{l}5.558 \\
3.618 \\
4.003 \\
5.124\end{array}$ & 4.576 & 2.744 & 59.9 \\
\hline
\end{tabular}


Pair Code: $\quad \mathrm{DUO}_{2}-40: \operatorname{Zr} 4-25$

ISM: II

Gas Composition HE (100\%)

Temperature: $\quad 673 \mathrm{~K}$

$\mathrm{D}_{\mathrm{mp}}$ :

$5.9 \pm 3.3 \mu \mathrm{m}(3 \sigma)$

(Specimens in light contact: $\approx 1300 \mathrm{~N} / \mathrm{m}^{2}$ )

\begin{tabular}{|c|c|c|c|c|c|}
\hline $\begin{array}{l}\text { Gas } \\
\text { Pressure } \\
(\mathrm{MPa})\end{array}$ & $\begin{array}{l}\text { Data } \\
\text { I.D.* }\end{array}$ & $\left(w / m^{2}-{ }^{H} \times 10^{-4}\right)$ & $\begin{array}{c}\text { Avg } H_{g} \\
\left(w / m^{2}-K \times 10^{-4}\right)\end{array}$ & $\begin{array}{c}3 \sigma_{R} \\
\left(w / m^{2}-k \times 10^{-4}\right) \\
\end{array}$ & $\begin{array}{l}3 \sigma_{R} \\
(\%)\end{array}$ \\
\hline 0.102 & $\begin{array}{l}J-28 \\
J-29 \\
J-30 \\
J-31\end{array}$ & $\begin{array}{l}2.795 \\
2.680 \\
2.618 \\
2.739\end{array}$ & 2.708 & 0.229 & 8.5 \\
\hline 0.200 & $\begin{array}{l}J-25 \\
J-26 \\
J-27\end{array}$ & $\begin{array}{l}3.987 \\
4.566 \\
3.972\end{array}$ & 4.172 & 1.016 & 24.4 \\
\hline 0.308 & $\begin{array}{l}J-22 \\
J-23 \\
J-24\end{array}$ & $\begin{array}{l}5.043 \\
5.007 \\
5.022\end{array}$ & 5.024 & 0.054 & 1.1 \\
\hline 0.518 & $\begin{array}{l}J-19 \\
J-20 \\
J-21\end{array}$ & $\begin{array}{l}5.345 \\
6.058 \\
6.876\end{array}$ & 6.093 & 2.298 & 37.7 \\
\hline 0.742 & $\begin{array}{l}\mathrm{J}-17 \\
\mathrm{~J}-18\end{array}$ & $\begin{array}{l}7.391 \\
8.584\end{array}$ & 7.986 & 2.531 & 31.7 \\
\hline 0.935 & $\begin{array}{l}J-13 \\
J-14 \\
J-15\end{array}$ & $\begin{array}{r}10.120 \\
10.480 \\
7.782\end{array}$ & 9.460 & 4.394 & 46.4 \\
\hline 1.16 & $\begin{array}{l}J-10 \\
J-11 \\
J-12\end{array}$ & $\begin{array}{l}7.882 \\
7.665 \\
8.592\end{array}$ & 8.046 & 1.454 & 18.1 \\
\hline 1.50 & $\begin{array}{l}J-7 \\
J-8 \\
J-9\end{array}$ & $\begin{array}{l}9.079 \\
9.536 \\
8.049\end{array}$ & 8.888 & 2.285 & 25.7 \\
\hline 2.02 & $\begin{array}{l}J-4 \\
J-5 \\
J-6\end{array}$ & $\begin{array}{l}7.999 \\
8.890 \\
9.553\end{array}$ & 8.814 & 2.339 & 26.5 \\
\hline
\end{tabular}


Pair Code:

ISM:

Gas Composition

Temperature:

$D_{m p}$ :

\begin{tabular}{|c|c|c|c|c|c|}
\hline $\begin{array}{l}\text { Gas } \\
\text { Pressure } \\
(\mathrm{MPa})\end{array}$ & $\begin{array}{l}\text { Data } \\
\text { I.D.* }\end{array}$ & $\left(w / m^{2}-K^{H_{g}} \times 10^{-4}\right)$ & $\begin{array}{c}\text { Avg } H_{g} \\
\left(w / m^{2}-K \times 10^{-4}\right)\end{array}$ & $\begin{array}{c}{ }^{3 \sigma_{R}} \\
\left(w / m^{2}-k \times 10^{-4}\right) \\
\end{array}$ & $\begin{array}{l}3 \sigma_{R} \\
(\%)\end{array}$ \\
\hline 3.00 & $\begin{array}{l}J-1 \\
J-2 \\
J-3\end{array}$ & $\begin{array}{l}7.709 \\
9.659 \\
8.110\end{array}$ & 8.492 & 3.089 & 36.4 \\
\hline 3.96 & $\begin{array}{l}I-47 \\
I-48 \\
I-49\end{array}$ & $\begin{array}{l}8.301 \\
6.950 \\
9.628\end{array}$ & 8.293 & 4.017 & 48.4 \\
\hline
\end{tabular}

$\mathrm{DUO}_{2}-40: \operatorname{Zr} 4-25$

II

HE (100\%)

$673 \mathrm{~K}$

$5.9+3.3 \mu \mathrm{m}(3 \sigma)$

(Specimens in light contact: $\approx 1300 \mathrm{~N} / \mathrm{m}^{2}$ ) 


$$
\begin{array}{ll}
\text { Pair Code: } & \text { DUO }_{2}-40: \operatorname{Zr} 4-25 \\
\text { ISM: } & \text { I I } \\
\text { Gas Composition } & \text { AR }(100 \%) \\
\text { Temperature: } & 283 \mathrm{~K} \\
\text { Dmp: } & 5.9 \pm 3.3 \mu \mathrm{m}(3 \sigma) \\
& \left(\text { Specimens in light contact: } \approx 1300 \mathrm{~N} / \mathrm{m}^{2}\right)
\end{array}
$$

\begin{tabular}{|c|c|c|c|c|c|}
\hline $\begin{array}{l}\text { Gas } \\
\text { Pressure } \\
\text { (MPa) }\end{array}$ & $\begin{array}{l}\text { Data } \\
\text { I.D.* }\end{array}$ & $\left(w / m^{2}-{ }_{g}{ }^{H} \times 10^{-4}\right)$ & $\begin{array}{c}\text { Avg } H_{g} \\
\left(w / m^{2}-K \times 10^{-4}\right) \\
\end{array}$ & $\begin{array}{c}{ }^{3 \sigma_{R}} \\
\left(w / m^{2}-k \times 10^{-4}\right) \\
\end{array}$ & $\begin{array}{l}{ }^{3 \sigma_{R}} \\
(\%)\end{array}$ \\
\hline 0.103 & $\begin{array}{l}C-30 \\
C-31 \\
C-32\end{array}$ & $\begin{array}{l}0.488 \\
0.489 \\
0.499\end{array}$ & $0.40 ?$ & 0.018 & 3.7 \\
\hline 0.30 & $\begin{array}{l}C-27 \\
C-28 \\
C-29\end{array}$ & $\begin{array}{l}0.516 \\
0.526 \\
0.540\end{array}$ & 0.527 & 0.036 & 6.8 \\
\hline 0.60 & $\begin{array}{l}C-24 \\
C-25 \\
C-26\end{array}$ & $\begin{array}{l}0.545 \\
0.544 \\
0.541\end{array}$ & 0.543 & 0.006 & 1.1 \\
\hline 1.00 & $\begin{array}{l}C-21 \\
C-22 \\
C-23\end{array}$ & $\begin{array}{l}0.542 \\
0.536 \\
0.530\end{array}$ & 0.536 & 0.018 & 3.4 \\
\hline 2.00 & $\begin{array}{l}C-18 \\
C-19 \\
C-20\end{array}$ & $\begin{array}{l}0.527 \\
0.557 \\
0.538\end{array}$ & 0.541 & 0.046 & 8.5 \\
\hline 3.00 & $\begin{array}{l}C-15 \\
C-16 \\
C-17\end{array}$ & $\begin{array}{l}0.575 \\
0.584 \\
0.555\end{array}$ & 0.572 & 0.045 & 7.9 \\
\hline 4.00 & $\begin{array}{l}C-12 \\
C-13 \\
C-14\end{array}$ & $\begin{array}{l}0.558 \\
0.598 \\
0.548\end{array}$ & 0.568 & 0.078 & 13.7 \\
\hline 5.00 & $\begin{array}{l}C-9 \\
C-10 \\
C-11\end{array}$ & $\begin{array}{l}0.552 \\
0.566 \\
0.559\end{array}$ & 0.559 & 0.021 & 3.8 \\
\hline 6.00 & $\begin{array}{l}C-6 \\
C-7 \\
C-8\end{array}$ & $\begin{array}{l}0.582 \\
0.614 \\
0.607\end{array}$ & 0.601 & 0.051 & 8.5 \\
\hline
\end{tabular}


Pair Code:

ISM:

Gas Composition

Temperature:

$\mathrm{D}_{\mathrm{mp}}$ :

Gas

Pressure (MPa)

7.00
C-1

C -2

C-3

C -4

C-5
$\mathrm{DUO}_{2}-40: \operatorname{Zr} 4-25$

II

$\operatorname{AR}(100 \%)$

283K

$5.9+3.3 \mu \mathrm{m}(3 \sigma)$

(Specimens in light contact: $\approx 1300 \mathrm{~N} / \mathrm{m}^{2}$ )

\begin{tabular}{|c|c|c|c|c|c|}
\hline $\begin{array}{l}\text { Gas } \\
\text { Pressure } \\
\text { (MPa) }\end{array}$ & $\begin{array}{l}\text { Oata } \\
\text { I.D.* }\end{array}$ & $\left(\mathrm{w} / \mathrm{m}^{2}-\mathrm{K} \times 10^{-4}\right)$ & $\begin{array}{l}\text { Avg } H_{g} \\
\left(w / m^{2}-K \times 10^{-4}\right)\end{array}$ & $\begin{array}{c}3 \sigma_{R} \\
\left(w / m^{2}-k \times 10^{-4}\right)\end{array}$ & $\begin{array}{l}3 \sigma_{R} \\
(\%)\end{array}$ \\
\hline 7.00 & $\begin{array}{l}C-1 \\
C-2 \\
C-3 \\
C-4 \\
C-5\end{array}$ & $\begin{array}{l}0.606 \\
0.600 \\
0.634 \\
0.608 \\
0.579\end{array}$ & 0.605 & 0.059 & 9.7 \\
\hline
\end{tabular}


Pair Code: $\quad \mathrm{DUO}_{2}-40: 7 r^{4}-25$

ISM: II

Gas Composition AR (100\%)

Temperature: $\quad 473 \mathrm{~K}$

$0_{\mathrm{mp}}$ :

$5.9+3.3 \mu \mathrm{m}(3 \sigma)$

(Specimens in light contact: $\approx 1300 \mathrm{~N} / \mathrm{m}^{2}$ )

\begin{tabular}{|c|c|c|c|c|c|}
\hline $\begin{array}{l}\text { Gas } \\
\text { Pressure } \\
\text { (MPa) }\end{array}$ & $\begin{array}{l}\text { Data } \\
\text { I.D.* }\end{array}$ & $\left(\mathrm{w} / \mathrm{m}^{2}-\mathrm{K}_{\mathrm{g}}^{\mathrm{H}_{\mathrm{g}}} \mathrm{0}^{-4}\right)$ & $\begin{array}{l}\text { Avg } H_{g} \\
\left(w / m^{2}-K \times 10^{-4}\right)\end{array}$ & $\begin{array}{c}{ }^{3 \sigma_{R}} \\
\left(w / m^{2}-K \times 10^{-4}\right)\end{array}$ & $\begin{array}{l}3 \sigma_{R} \\
(\%)\end{array}$ \\
\hline 0.102 & $\begin{array}{l}\mathrm{G}-20 \\
\mathrm{G}-21 \\
\mathrm{G}-22\end{array}$ & $\begin{array}{l}0.630 \\
0.619 \\
0.020\end{array}$ & 0.623 & 0.020 & 3.1 \\
\hline 0.25 & $\begin{array}{l}\text { G-16 } \\
\text { G-17 } \\
\text { G-18 } \\
\text { G-19 }\end{array}$ & $\begin{array}{l}0.814 \\
0.687 \\
0.710 \\
0.698\end{array}$ & 0.727 & 0.176 & 24.2 \\
\hline 0.45 & $\begin{array}{l}G-13 \\
G-14 \\
G-15\end{array}$ & $\begin{array}{l}0.754 \\
0.756 \\
0.765\end{array}$ & 0.758 & 0.017 & 2.3 \\
\hline 0.64 & $\begin{array}{l}G-10 \\
G-11 \\
G-12\end{array}$ & $\begin{array}{l}0.767 \\
0.808 \\
0.777\end{array}$ & 0.784 & 0.064 & 8.1 \\
\hline 0.80 & $\begin{array}{l}G-7 \\
G-8 \\
G-9\end{array}$ & $\begin{array}{l}0.854 \\
0.767 \\
0.819\end{array}$ & 0.813 & 0.131 & 16.1 \\
\hline 0.99 & $\begin{array}{l}G-4 \\
G-5 \\
G-6\end{array}$ & $\begin{array}{l}0.877 \\
0.917 \\
0.911\end{array}$ & 0.901 & 0.064 & 7.1 \\
\hline 1.54 & $\begin{array}{l}G-1 \\
G-2 \\
G-3\end{array}$ & $\begin{array}{l}0.831 \\
0.903 \\
0.949\end{array}$ & 0.894 & 0.178 & 19.9 \\
\hline 4.03 & $\begin{array}{l}F-49 \\
F-50 \\
F-51 \\
F-52 \\
F-53 \\
F-54 \\
F-55\end{array}$ & $\begin{array}{l}0.899 \\
0.741 \\
0.873 \\
0.798 \\
0.751 \\
0.769 \\
0.806\end{array}$ & 0.805 & 0.181 & 22.5 \\
\hline
\end{tabular}

A. 9 


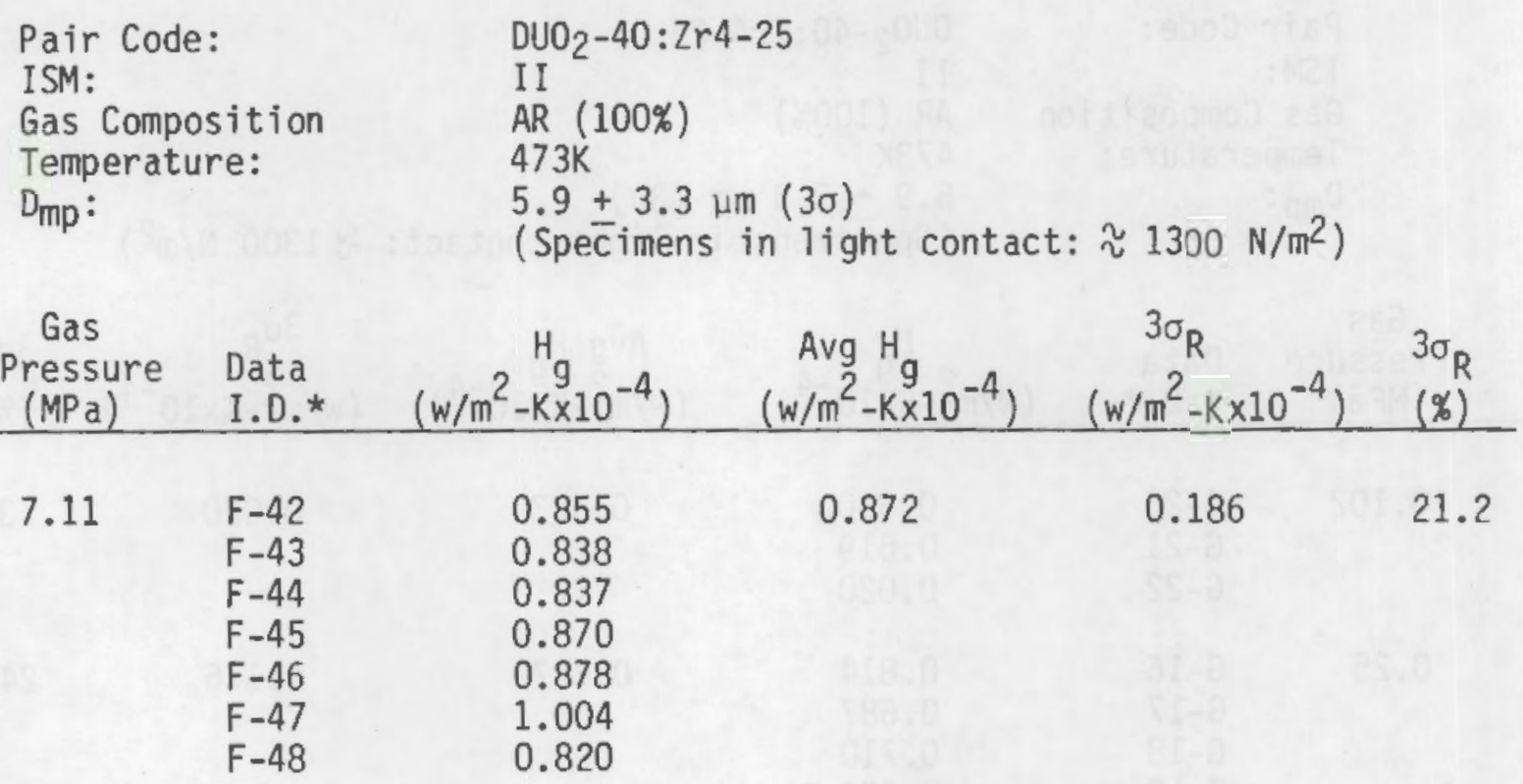


Pair Code: $\quad$ OU02-40:Zr4-25

ISM:

II

Gas Composition

Temperature:

$\mathrm{D}_{\mathrm{mp}}$ :

$\mathrm{He}(51.79 \%): \operatorname{Ar}(48.21 \%)$

283K

$5.9 \pm 3.3 \mu \mathrm{m}(3 \sigma)$

(Specimens in light contact: $\approx 1300 \mathrm{~N} / \mathrm{m}^{2}$ )

\begin{tabular}{|c|c|c|c|c|c|}
\hline $\begin{array}{l}\text { Gas } \\
\text { Pressure } \\
\text { (MPa) }\end{array}$ & $\begin{array}{l}\text { Data } \\
\text { I.0.* }\end{array}$ & $\left(w / m^{2}-K_{g}^{H_{g}} \times 10^{-4}\right)$ & $\begin{array}{c}\text { Avg } H_{g} \\
\left(\mathrm{w} / \mathrm{m}^{2}-\mathrm{K} \times 10^{-4}\right)\end{array}$ & $\begin{array}{c}3 \sigma_{R} \\
\left(w / m^{2}-K \times 10^{-4}\right) \\
\end{array}$ & $\begin{array}{l}{ }^{3 \sigma_{R}} \\
(\%)\end{array}$ \\
\hline 0.102 & $\begin{array}{l}\mathrm{C}-33 \\
\mathrm{C}-34 \\
\mathrm{C}-35 \\
\mathrm{D}-22 \\
\mathrm{D}-23 \\
\mathrm{D}-24 \\
\mathrm{H}-3 \\
\mathrm{H}-4 \\
\mathrm{H}-5\end{array}$ & $\begin{array}{l}1.093 \\
1.053 \\
1.061 \\
1.086 \\
1.080 \\
1.069 \\
0.999 \\
0.982 \\
0.992\end{array}$ & 1.046 & 0.130 & 12.4 \\
\hline 0.20 & $\begin{array}{l}C-36 \\
C-37 \\
C-38\end{array}$ & $\begin{array}{l}1.919 \\
1.174 \\
1.174\end{array}$ & 1.180 & 0.029 & 2.5 \\
\hline 0.30 & $\begin{array}{l}C-39 \\
C-40 \\
C-41\end{array}$ & $\begin{array}{l}1.182 \\
1.236 \\
1.224\end{array}$ & 1.214 & 0.085 & 7.0 \\
\hline 0.40 & $\begin{array}{l}\text { C-42 } \\
\text { C-43 } \\
\text { C-44 }\end{array}$ & $\begin{array}{l}1.268 \\
1.253 \\
1.199\end{array}$ & 1.240 & 0.104 & 8.3 \\
\hline 0.60 & $\begin{array}{l}C-45 \\
C-46 \\
C-47\end{array}$ & $\begin{array}{l}1.261 \\
1.246 \\
1.223\end{array}$ & 1.243 & 0.057 & 4.6 \\
\hline 0.80 & $\begin{array}{l}C-48 \\
C-49 \\
C-50\end{array}$ & $\begin{array}{l}1.208 \\
1.290 \\
1.274\end{array}$ & 1.257 & 0.130 & 10.3 \\
\hline 1.00 & $\begin{array}{l}C-51 \\
C-52\end{array}$ & $\begin{array}{l}1.232 \\
1.244\end{array}$ & 1.238 & 0.025 & 2.0 \\
\hline 1.50 & $\begin{array}{l}0-2 \\
0-3 \\
0-4\end{array}$ & $\begin{array}{l}1.250 \\
1.261 \\
1.275\end{array}$ & 1.262 & 0.038 & 3.0 \\
\hline
\end{tabular}


Pair Code:

ISM:

Gas Composition

Temperature:

$\mathrm{D}_{\mathrm{mp}}$ :

$$
\begin{aligned}
& \mathrm{DUO}_{2}-40: \mathrm{Zr} 4-25 \\
& \text { I I } \\
& \mathrm{He}(51.79 \%): \mathrm{Ar}(48.21 \%) \\
& 283 \mathrm{~K} \\
& 5.9 \pm 3.3 \mu \mathrm{m}(3 \sigma)
\end{aligned}
$$

\begin{tabular}{|c|c|c|c|c|c|}
\hline $\begin{array}{c}\text { Gas } \\
\text { Pressure } \\
(\mathrm{MPa}) \\
\end{array}$ & $\begin{array}{l}\text { Data } \\
\text { I.D.* }\end{array}$ & $\left(\mathrm{w} / \mathrm{m}^{2}-\mathrm{K}_{\mathrm{g}}^{\mathrm{H}_{10}} \mathrm{0}^{-4}\right)$ & $\begin{array}{c}\text { Avg } H_{g} \\
\left(w / m^{2}-K \times 10^{-4}\right)\end{array}$ & $\begin{array}{c}{ }^{3 \sigma_{R}} \\
\left(w / m^{2}-k \times 10^{-4}\right)\end{array}$ & $\begin{array}{l}3 \sigma_{\mathrm{R}} \\
(\%)\end{array}$ \\
\hline 2.00 & $\begin{array}{l}D-5 \\
D-6\end{array}$ & $\begin{array}{l}1.232 \\
1.209\end{array}$ & 1.221 & 0.049 & 4.0 \\
\hline 3.00 & $\begin{array}{l}D-7 \\
D-8\end{array}$ & $\begin{array}{l}1.240 \\
1.249\end{array}$ & 1.245 & 0.019 & 1.6 \\
\hline 4.00 & $\begin{array}{l}D-9 \\
D-10 \\
D-11\end{array}$ & $\begin{array}{l}1.245 \\
1.267 \\
1.243\end{array}$ & 1.251 & 0.040 & 3.2 \\
\hline 5.00 & $\begin{array}{l}D-12 \\
0-13 \\
D-14\end{array}$ & $\begin{array}{l}1.239 \\
1.230 \\
1.295\end{array}$ & 1.255 & 0.106 & 8.4 \\
\hline 6.00 & $\begin{array}{l}0-15 \\
D-16 \\
0-17\end{array}$ & $\begin{array}{l}1.293 \\
1.242 \\
1.239\end{array}$ & 1.258 & 0.091 & 7.2 \\
\hline 7.00 & $\begin{array}{l}D-18 \\
D-19 \\
D-20 \\
D-21\end{array}$ & $\begin{array}{l}1.262 \\
1.254 \\
1.269 \\
1.310\end{array}$ & 1.273 & 0.075 & 5.9 \\
\hline
\end{tabular}

(Specimens in light contact: $\approx 1300 \mathrm{~N} / \mathrm{m}^{2}$ ) 


\begin{tabular}{|c|c|c|c|c|c|}
\hline \multirow[b]{2}{*}{$\begin{array}{c}\text { Gas } \\
\text { Pressure } \\
\text { (MPa) } \\
\end{array}$} & \multicolumn{4}{|c|}{$\begin{array}{l}\mathrm{OUO}_{2}-40: \operatorname{Zr} 4-25 \\
\mathrm{II} \\
\mathrm{He}(51.79 \%): \operatorname{Ar}(48.21 \%) \\
473 \mathrm{~K} \\
5.9 \pm 3.3 \mu \mathrm{m}(3 \sigma) \\
\left.\text { (Specimens in 1ight contact: } \approx 1310 \mathrm{~N} / \mathrm{m}^{2}\right)\end{array}$} & \multirow[b]{2}{*}{$\begin{array}{l}3 \sigma_{R} \\
(\%) \\
\end{array}$} \\
\hline & $\begin{array}{l}\text { Data } \\
\text { I.D.* }\end{array}$ & $\left(\mathrm{w} / \mathrm{m}^{2}-\mathrm{K}_{\mathrm{g}}^{\mathrm{H}} \times 10^{-4}\right)$ & $\begin{array}{c}\text { Avg } H_{g} \\
\left(\mathrm{w} / \mathrm{m}^{2}-\mathrm{K} \times 10^{-4}\right) \\
\end{array}$ & $\begin{array}{c}3 \sigma_{R} \\
\left(w / m^{2}-k \times 10^{-4}\right) \\
\end{array}$ & \\
\hline 0.102 & $\begin{array}{l}\text { G-26 } \\
\text { G-27 } \\
\text { G-28 }\end{array}$ & $\begin{array}{l}1.291 \\
1.306 \\
1.311\end{array}$ & 1.303 & 0.031 & 2.4 \\
\hline 0.31 & $\begin{array}{l}G-29 \\
G-30 \\
G-31\end{array}$ & $\begin{array}{l}1.688 \\
1.701 \\
1.702\end{array}$ & 1.697 & 0.023 & 1.4 \\
\hline 0.47 & $\begin{array}{l}G-32 \\
G-33 \\
G-34\end{array}$ & $\begin{array}{l}1.627 \\
1.813 \\
1.833\end{array}$ & 1.758 & 0.340 & 19.4 \\
\hline 0.69 & $\begin{array}{l}G-35 \\
G-36 \\
G-37\end{array}$ & $\begin{array}{l}1.805 \\
1.814 \\
1.868\end{array}$ & 1.829 & 0.102 & 5.6 \\
\hline 0.94 & $\begin{array}{l}G-38 \\
G-39 \\
G-40\end{array}$ & $\begin{array}{l}1.804 \\
1.834 \\
1.801\end{array}$ & 1.813 & 0.055 & 3.0 \\
\hline 1.18 & $\begin{array}{l}G-41 \\
G-42 \\
G-43\end{array}$ & $\begin{array}{l}1.860 \\
1.819 \\
1.845\end{array}$ & 1.841 & 0.062 & 3.4 \\
\hline 1.61 & $\begin{array}{l}\text { G-44 } \\
\text { G-45 } \\
\text { G-46 }\end{array}$ & $\begin{array}{l}1.745 \\
1.926 \\
1.762\end{array}$ & 1.811 & 0.299 & 16.6 \\
\hline 2.18 & $\begin{array}{l}G-47 \\
G-48\end{array}$ & $\begin{array}{l}1.867 \\
2.210\end{array}$ & 2.039 & 0.730 & 35.7 \\
\hline 3.88 & $\begin{array}{l}G-50 \\
G-51 \\
G-52\end{array}$ & $\begin{array}{l}1.568 \\
1.870 \\
2.030\end{array}$ & 1.866 & 0.527 & 28.8 \\
\hline 5.61 & $\begin{array}{l}\text { G-53 } \\
\text { G-54 } \\
H-1 \\
H-2\end{array}$ & $\begin{array}{l}2.143 \\
1.850 \\
1.833 \\
1.926\end{array}$ & 1.951 & 0.396 & 20.3 \\
\hline
\end{tabular}




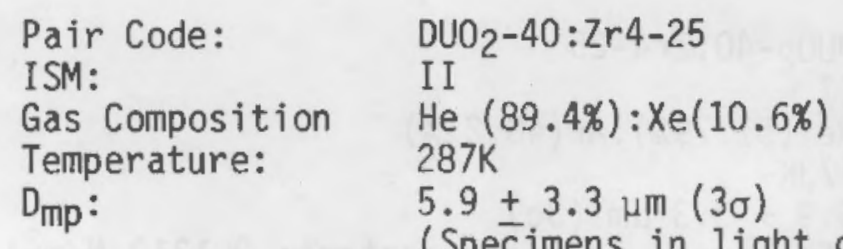

(Specimens in light contact: $\approx 1300 \mathrm{~N} / \mathrm{m}^{2}$ )

\begin{tabular}{|c|c|c|c|c|c|}
\hline $\begin{array}{c}\text { Gas } \\
\text { Pressure } \\
\text { (MPa) }\end{array}$ & $\begin{array}{l}\text { Data } \\
\text { I.D.* }\end{array}$ & $\left(\mathrm{w} / \mathrm{m}^{2}-\mathrm{K}_{\mathrm{g}}^{\mathrm{H}_{\mathrm{g}}} \mathrm{0}^{-4}\right)$ & $\begin{array}{l}\text { Avg } H_{g} \\
\left(w / m^{2}-K \times 10^{-4}\right)\end{array}$ & $\begin{array}{c}3 \sigma_{R} \\
\left(w / m^{2}-k \times 10^{-4}\right)\end{array}$ & $\begin{array}{l}3 \sigma_{R} \\
(\%)\end{array}$ \\
\hline 0.102 & $\begin{array}{l}H-6 \\
H-7 \\
H-8 \\
I-40 \\
I-41 \\
I-42\end{array}$ & $\begin{array}{l}1.743 \\
1.750 \\
1.684 \\
1.456 \\
1.431 \\
1.439\end{array}$ & 1.584 & 0.471 & 29.8 \\
\hline 0.21 & $\begin{array}{l}H-9 \\
H-10 \\
H-11\end{array}$ & $\begin{array}{l}1.743 \\
1.802 \\
1.798\end{array}$ & 1.781 & 0.099 & 5.5 \\
\hline 0.31 & $\begin{array}{l}\mathrm{H}-12 \\
\mathrm{H}-13 \\
\mathrm{H}-14\end{array}$ & $\begin{array}{l}1.848 \\
1.872 \\
1.760\end{array}$ & 1.827 & 0.177 & 9.7 \\
\hline 0.45 & $\begin{array}{l}\mathrm{H}-15 \\
\mathrm{H}-16 \\
\mathrm{H}-17\end{array}$ & $\begin{array}{l}1.958 \\
1.986 \\
1.960\end{array}$ & 1.968 & 0.047 & 2.4 \\
\hline 0.62 & $\begin{array}{l}H-18 \\
H-19 \\
H-20\end{array}$ & $\begin{array}{l}1.876 \\
1.883 \\
1.927\end{array}$ & 1.895 & 0.083 & 4.3 \\
\hline 0.79 & $\begin{array}{l}H-21 \\
H-22 \\
H-23\end{array}$ & $\begin{array}{l}1.983 \\
2.069 \\
2.019\end{array}$ & 2.024 & 0.129 & 6.3 \\
\hline 0.96 & $\begin{array}{l}H-24 \\
H-25 \\
H-26\end{array}$ & $\begin{array}{l}2.039 \\
1.995 \\
2.022\end{array}$ & 2.019 & 0.067 & 3.2 \\
\hline 1.13 & $\begin{array}{l}\mathrm{H}-27 \\
\mathrm{H}-28 \\
\mathrm{H}-2 \mathrm{O}\end{array}$ & $\begin{array}{l}1.959 \\
1.931 \\
1.981\end{array}$ & 1.957 & 0.075 & 3.8 \\
\hline 1.49 & $\begin{array}{l}H-30 \\
H-31 \\
H-32\end{array}$ & $\begin{array}{l}1.922 \\
1.873 \\
1.990\end{array}$ & 1.928 & 0.176 & 9.1 \\
\hline
\end{tabular}


Pair Code:

ISM:

Gas Composition

Temperature:

$D_{\mathrm{mp}}$ :

Gas

Pressure

(MPa)

2.01

$\mathrm{H}-33$

$\mathrm{H}-34$

$\mathrm{H}-35$

3.00

$\mathrm{H}-36$

$\mathrm{H}-37$

$\mathrm{H}-38$

4.00

$\mathrm{H}-39$

$\mathrm{H}-40$

$\mathrm{H}-41$

5.00

$\mathrm{H}-42$

$\mathrm{H}-43$

$\mathrm{H}-44$

6.00
$\mathrm{DUO}_{2}-40: \mathrm{Zr} 4-25$

I I

$\mathrm{He}(89.4 \%): \mathrm{Xe}(10.6 \%)$

$287 \mathrm{~K}$

$5.9+3.3 \mu \mathrm{m}(3 \sigma)$

(Specimens in light contact: $\approx 1300 \mathrm{~N} / \mathrm{m}^{2}$ )

$\begin{array}{lllll}\mathrm{H}-45 & 1.669 & 1.744 & 0.326 & 18.7 \\ \mathrm{H}-46 & 1.707 & & & \\ \mathrm{H}-47 & 1.692 & & & \\ \mathrm{H}-48 & 1.905 & & & \end{array}$



Pair Code:
ISM:
$\mathrm{DUO}_{2}-40: \mathrm{Zr} 4-25$
Gas Composition
Temperature:
II
$\mathrm{D}_{\mathrm{mp}}$ :
He $(89.4 \%): \mathrm{Xe}(10.5 \%)$
$473 \mathrm{~K}$
$5.9+3.3 \mu \mathrm{m}(3 \sigma)$

(Specimens in light contact: $\approx 1300 \mathrm{~N} / \mathrm{m}^{2}$ )

Gas

Gas

(MPa)

Data I.D.*

$\left(w / m^{2}-x \times 10^{-4}\right)$

Avg $\mathrm{H}_{\mathrm{g}}$

$3 \sigma_{R}$

R

0.102

I-36

I -37

I -38

I-39

$\left(w / m^{2}-x \times 10^{-4}\right.$

$\left(w / m^{2}-K \times 10^{-4}\right)$

$3 \sigma_{R}$

(\%)

$\begin{array}{ll}I-33 & 2.804 \\ I-34 & 2.657 \\ I-35 & 2.821\end{array}$

0.32

I -30

3.197

3.022

2.410

2.255

0.327

14.5

0.205

I -31

3.197

0.52

3.587

3.680

I -27

3.714

2.761

0.271

9.8

I -29

3.138

0.303

9.6

0.72

I -25

3.778

3.853

0.318

8.3

I -26

3.928

0.91

I-21

I -22

3.886

4.230

I-23

4.380

1.11

\section{I -18}

I -19

4.020

3.720

I-20

3.823

4.163

0.760

18.2

1.47

$I-15$
I -16
I -17

3.713

4.135

3.911

0.637

16.3

3.885

1.97

$\mathrm{I}-12$
$\mathrm{I}-13$
$\mathrm{I}-14$

4.231

3.276

3.873

0.562

40.3 
Pair Code:

ISM:

GaS Composition

Temperature:

$\mathrm{D}_{\mathrm{mp}}$ :
$\mathrm{DUO}_{2}-40: \mathrm{Zr} 4-25$

II

He $(89.4 \%): X e(10.5 \%)$

$473 \mathrm{~K}$

$5.9 \pm 3.3 \mu \mathrm{m}(3 \sigma)$

(Specimens in light contact: $\approx 1300 \mathrm{~N} / \mathrm{m}^{2}$ )

\begin{tabular}{|c|c|c|c|c|c|}
\hline $\begin{array}{l}\text { Gas } \\
\text { Pressure } \\
\text { (MPa) } \\
\end{array}$ & $\begin{array}{l}\text { Data } \\
\text { I.D.* }\end{array}$ & $\left(\mathrm{w} / \mathrm{m}^{2}-\mathrm{K}_{\mathrm{g}}^{\mathrm{H}} \mathrm{H}^{\mathrm{H}} 0^{-4}\right)$ & $\begin{array}{c}\text { Avg } H_{g} \\
\left(\mathrm{w} / \mathrm{m}^{2}-\mathrm{K} \times 10^{-4}\right)\end{array}$ & $\begin{array}{c}{ }^{3 \sigma_{R}} \\
\left(w / m^{2}-k \times 10^{-4}\right) \\
\end{array}$ & $\begin{array}{l}3 \sigma_{\mathrm{R}} \\
(\%)\end{array}$ \\
\hline 2.93 & $\begin{array}{l}I-9 \\
I-10 \\
I-11\end{array}$ & $\begin{array}{l}3.781 \\
3.262 \\
3.949\end{array}$ & 3.664 & 1.074 & 29.3 \\
\hline 4.00 & $\begin{array}{l}I-6 \\
I-7 \\
I-8\end{array}$ & $\begin{array}{l}4.063 \\
3.602 \\
3.852\end{array}$ & 3.830 & 0.654 & 17.1 \\
\hline 4.98 & $\begin{array}{l}I-3 \\
I-4 \\
I-5\end{array}$ & $\begin{array}{l}3.545 \\
3.610 \\
2.772\end{array}$ & 3.309 & 1.399 & 42.3 \\
\hline 6.02 & $\begin{array}{l}H-50 \\
I-1 \\
I-2\end{array}$ & $\begin{array}{l}2.947 \\
3.667 \\
3.445\end{array}$ & 3.353 & 1.106 & 33.0 \\
\hline
\end{tabular}




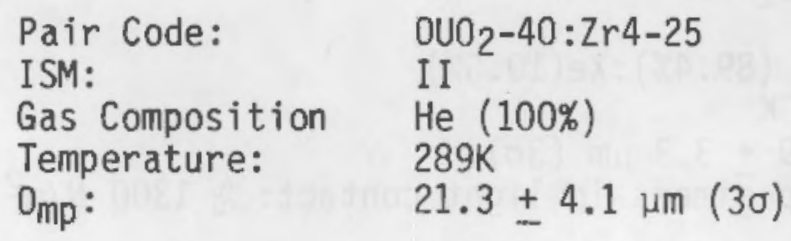

\begin{tabular}{|c|c|c|c|c|c|}
\hline $\begin{array}{c}\text { Gas } \\
\text { Pressure } \\
\text { (MPa) }\end{array}$ & $\begin{array}{l}\text { Oata } \\
\text { I.0.* }\end{array}$ & $\left(w / m^{2}-K \times 10^{-4}\right)$ & $\begin{array}{l}\text { Avg } H_{g} \\
\left(\mathrm{w} / \mathrm{m}^{2}-\mathrm{K} \times 10^{-4}\right)\end{array}$ & $\begin{array}{c}{ }^{3 \sigma_{R}} \\
\left(w / m^{2}-K \times 10^{-4}\right)\end{array}$ & $\begin{array}{l}3 \sigma_{R} \\
(\%)\end{array}$ \\
\hline 0.102 & $\begin{array}{l}J-35 \\
J-36 \\
J-37 \\
L-11 \\
L-12 \\
L-13\end{array}$ & $\begin{array}{l}0.722 \\
0.682 \\
0.564 \\
0.648 \\
0.718 \\
0.758\end{array}$ & 0.699 & 0.124 & 17.7 \\
\hline 0.27 & $\begin{array}{l}J-38 \\
J-39 \\
J-40\end{array}$ & $\begin{array}{l}0.719 \\
0.726 \\
0.736\end{array}$ & 0.727 & 0.027 & 3.7 \\
\hline 0.45 & $\begin{array}{l}J-41 \\
J-42 \\
J-43\end{array}$ & $\begin{array}{l}0.725 \\
0.754 \\
0.760\end{array}$ & 0.747 & 0.055 & 7.4 \\
\hline 0.62 & $\begin{array}{l}J-44 \\
J-46\end{array}$ & $\begin{array}{l}0.718 \\
0.736\end{array}$ & 0.727 & 0.039 & 5.4 \\
\hline 0.79 & $3-47$ & 0.743 & 0.743 & - & - \\
\hline 0.96 & $\begin{array}{l}K-1 \\
K-2 \\
K-3 \\
K-4\end{array}$ & $\begin{array}{l}0.886 \\
0.737 \\
0.769 \\
0.738\end{array}$ & 0.776 & 0.173 & 22.4 \\
\hline 1.13 & $\begin{array}{l}K-5 \\
K-6 \\
k-7\end{array}$ & $\begin{array}{l}0.742 \\
0.748 \\
0.781\end{array}$ & 0.757 & 0.063 & 8.3 \\
\hline 1.50 & $\begin{array}{l}K-8 \\
K-9 \\
K-10\end{array}$ & $\begin{array}{l}0.765 \\
0.737 \\
0.726\end{array}$ & 0.743 & 0.060 & 8.1 \\
\hline 2.00 & $\begin{array}{l}k-11 \\
k-12 \\
k-13\end{array}$ & $\begin{array}{l}0.755 \\
0.724 \\
0.747\end{array}$ & 0.742 & 0.049 & 6.6 \\
\hline 3.00 & $\begin{array}{l}K-14 \\
K-15 \\
K-16\end{array}$ & $\begin{array}{l}0.583 \\
0.720 \\
0.678\end{array}$ & 0.693 & 0.068 & 9.8 \\
\hline
\end{tabular}


Pair Code:

ISM:

Gas Composition

Temperature:

$\mathrm{O}_{\mathrm{mp}}$ :

Gas

Pressure

(MPa)

4.00

$\mathrm{K}-17$

$\mathrm{K}-18$

$\mathrm{K}-19$

5.00

$$
\mathrm{K}-20
$$

$\mathrm{K}-21$

$\mathrm{K}-22$

6.00

$\mathrm{k}-23$

$\mathrm{K}-24$

$\mathrm{K}-25$

7.00

$\mathrm{K}-25$

$\mathrm{K}-27$

$\mathrm{K}-28$

$\mathrm{K}-29$
$\mathrm{DUO}_{2}-40: \operatorname{Zr} 4-25$

II

$\mathrm{He}(100 \%)$

$289 \mathrm{~K}$

$21.3 \pm 4.1 \mu \mathrm{m}(3 \sigma)$ 


\begin{tabular}{|c|c|c|c|c|c|}
\hline \multicolumn{2}{|c|}{$\begin{array}{l}\text { Pair Code: } \\
\text { ISM: } \\
\text { Gas Composition } \\
\text { Temperature: } \\
\text { Dmp: }\end{array}$} & \multicolumn{2}{|c|}{$\begin{array}{l}\mathrm{DUO}_{2}-40: \mathrm{Zr} 4-25 \\
\text { II } \\
\mathrm{He}(100) \\
673 \mathrm{~K} \\
21.3 \pm 4.1 \mu \mathrm{m}(3 \sigma)\end{array}$} & \multirow[b]{2}{*}{$\begin{array}{c}3 \sigma_{R} \\
\left(w / m^{2}-K \times 10^{-4}\right)\end{array}$} & \multirow[b]{2}{*}{$\begin{array}{l}3 \sigma_{R} \\
(x)\end{array}$} \\
\hline $\begin{array}{c}\text { Gas } \\
\text { Pressure } \\
\text { (MPa) }\end{array}$ & $\begin{array}{l}\text { Data } \\
\text { I.D.* }\end{array}$ & $\left(\mathrm{w} / \mathrm{m}^{2}-\mathrm{K}_{\mathrm{g}}^{\mathrm{H}} \times 10^{-4}\right)$ & $\begin{array}{c}\text { Avg }{ }^{H} g \\
\left(w / m^{2}-K \times 10^{-4}\right)\end{array}$ & & \\
\hline 0.102 & $\begin{array}{l}L-8 \\
L-9 \\
L-10\end{array}$ & $\begin{array}{l}1.459 \\
1.373 \\
1.374\end{array}$ & 1.402 & 0.148 & 10.6 \\
\hline 0.267 & $\begin{array}{l}L-5 \\
L-6 \\
L-7\end{array}$ & $\begin{array}{l}1.612 \\
1.649 \\
1.657\end{array}$ & 1.639 & 0.072 & 4.4 \\
\hline 0.45 & $\begin{array}{l}L-2 \\
L-3 \\
L-4\end{array}$ & $\begin{array}{l}1.715 \\
1.645 \\
1.711\end{array}$ & 1.690 & 0.118 & 7.0 \\
\hline 0.64 & $\begin{array}{l}K-49 \\
\text { K-50 } \\
\text { L-1 }\end{array}$ & $\begin{array}{l}2.457 \\
2.002 \\
1.806\end{array}$ & 2.088 & 1.002 & 48.0 \\
\hline 0.80 & $\begin{array}{l}\mathrm{K}-46 \\
\mathrm{~K}-47 \\
\mathrm{~K}-48\end{array}$ & $\begin{array}{l}2.749 \\
2.899 \\
2.622\end{array}$ & 2.757 & 0.416 & 15.1 \\
\hline 0.98 & $\begin{array}{l}K-43 \\
K-44 \\
K-45\end{array}$ & $\begin{array}{l}2.843 \\
3.256 \\
2.581\end{array}$ & 2.893 & 1.021 & 35.2 \\
\hline 1.14 & $\begin{array}{l}K-41 \\
K-42\end{array}$ & $\begin{array}{l}2.741 \\
2.581\end{array}$ & 2.661 & 0.339 & 12.6 \\
\hline 1.54 & $\begin{array}{l}K-37 \\
K-38 \\
K-39\end{array}$ & $\begin{array}{l}2.919 \\
3.163 \\
2.643\end{array}$ & 2.008 & 0.780 & 26.8 \\
\hline 2.06 & $\begin{array}{l}K-34 \\
K-35 \\
K-36\end{array}$ & $\begin{array}{l}2.968 \\
3.209 \\
2.438\end{array}$ & 2.872 & 1.183 & 41.2 \\
\hline 2.98 & $\begin{array}{l}K-30 \\
K-31 \\
K-32 \\
K-33\end{array}$ & $\begin{array}{l}2.601 \\
2.597 \\
3.280 \\
2.748\end{array}$ & 2.807 & 0.97 & 34.6 \\
\hline
\end{tabular}




\section{APPENDIX B}

SURFACE CHARACTERIZATION OF MPD SPECIMENS 


\section{B.0 SURFACE CHARACTERIZATION OF MPD SPECIMENS}

\section{B.1 OPTICAL HEIGHT GAGE CHARACTERIZATION}

Figure B.1 shows the coordinate positions on the sample surface at which the local height elevations were measured. Table B.1 contains the calculated local gap between asperity tips $\left(D_{a}\right)_{j}$ and the average gap between asperity tips $D_{a}$ for the $\mathrm{DUO}_{2}-40 ; \mathrm{Zr} 4-25$ specimen pair used in this study.

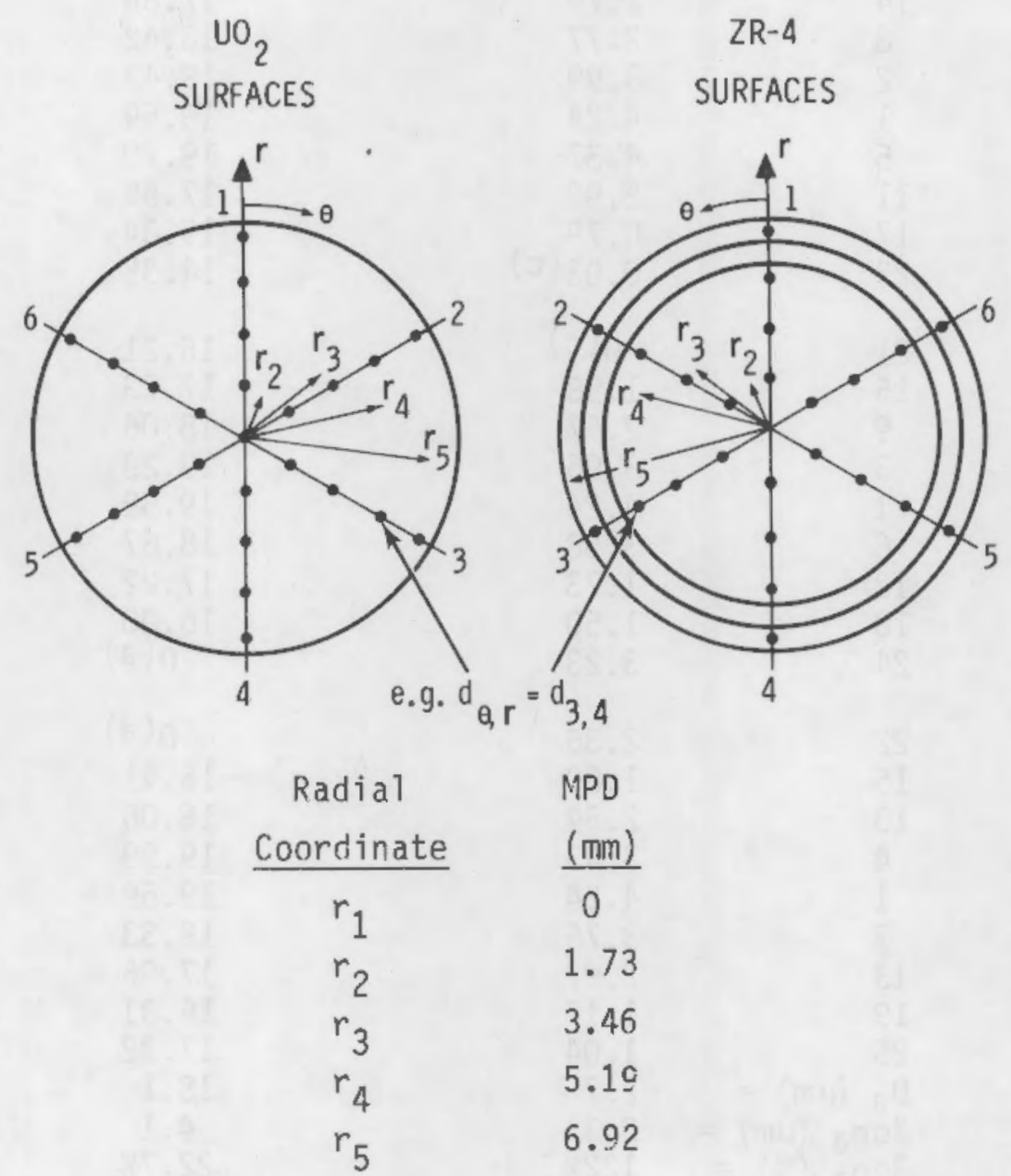

FIGURE B.1. Coordinate Positions Used in the Optical Height Gage Technique for Surface Characterization of MPD Specimens 
TABLE B.1. Local ( $\left.D_{a}\right)_{1}$ and Average D Gaps Between Asperity ${ }^{\mathrm{T}}$ PS for DUO -40 ? $\mathrm{Zr}$ 4-25 MPD Specimen Pair (ISM-II) as Calcalated from Dptical Height Gage Measurements

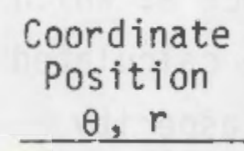

Index $i$

1,5

1,4

1,3

1,2

1,1

4,2

4,3

4,4

4,5

2,5

2,4

2,3

2,2

1,1

5,2

5,3

5,4

5,5

3,5

3,4

3,3

3,2

1,1

6,2

6,3

6,4

6,5
20

14

8

2

1

5

11

17

23

21

1.5

9

3

1

6

12

18

24

22

16

10

4

1

13

19

25

$\mathrm{D}_{\mathrm{a}}(\mu \mathrm{m})=$ $3 \sigma 0 \mathrm{a}(\mu \mathrm{m})=$ $3 \sigma_{0 a}(\%)$

$$
\mathrm{DUO}_{2}-40: \mathrm{Zr} 4-25
$$$$
\left(D_{a}\right)_{i}(b)(\mu m)
$$

0 (c)

1.79

2.77

3.99

4.24

4.37

2. 9 ?

0.79

0.03 (c)

0 (c)

1.98

2.57

3.96

4.24

3.58

1.73

1.50

3.23

2.36

1.80

2.54

3.43

4.24

3.76

2.07

1.17

1.04

2.7

3.3

122\%
$\mathrm{DUO}_{2}-40: 7 r-25$

$\left(D_{a}\right)_{i}(\mu \mathrm{m})$

0(a)

17.85

18.42

19.43

19.69

19.70

17.55

15.34

14.35

16.21

17.73

18.06

19.28

10.59

18.67

17.22

16.00

o(a)

$0(a)$

16.41

18.06

19.99

10.69

19.33

17.96

16.31

17.22

18.1

4.1

$22.7 \%$

\footnotetext{
(a) Spacer location.

(b) Calculated under light contact conditions

(c) Contact spot (assumed).
} 


\section{B.2 PROFILOMETER TRACES}

Figure B.2 shows typical profilometer traces obtained on the ISM-II $\mathrm{DUO}_{2}$ and $\mathrm{Zr} 4$ specimen surfaces. Table B.2 summarizes the CLA and $r$ values for all surfaces.

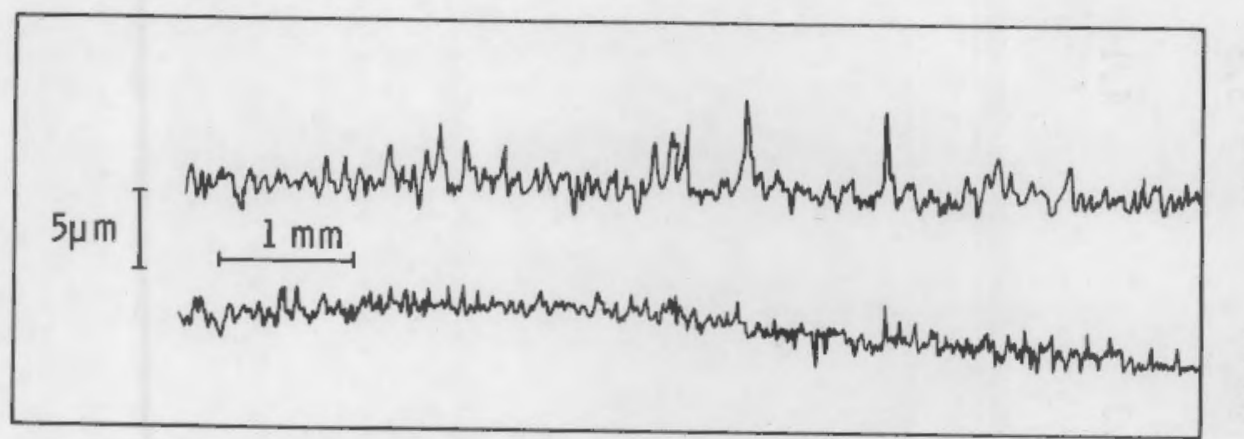

$\mathrm{DUO}_{2}$ ISM II

$C L A=1.6 \mu \mathrm{m}$

ZR4 ISM II

$C L A=0.4 \mu \mathrm{m}$

FIGURE B.2. Typical Profilometer Traces of an ISM-II $\mathrm{DUO}_{2}$ and $\mathrm{Zr} 4$ Surface

TABLE B.2. CLA $1, C_{1}, x, 1$ Values for the ISM-II Surfaces

\begin{tabular}{|c|c|c|c|c|}
\hline${ }_{C L A}^{(a)}(\mu \mathrm{m})$ & $3(\mu \mathrm{m})$ & $x^{(b)}(\mathrm{cm})$ & $(\mu \mathrm{m})$ & $3 \sigma(\mu \mathrm{m})$ \\
\hline 1.6 & 0.7 & 1 & 1.8 & 1.1 \\
\hline 0.4 & 0.2 & 1 & 1.4 & 0.5 \\
\hline
\end{tabular}

(a) Cut-off wavelength $=760 \mu \mathrm{m}$.

(b) Averaging interval used to determine the position of the mean-plane (line).

\section{B.3 AVERAGE MEAN-PLANE GAP}

Table B.3 summarizes the values obtained for the average mean-plane gap $\left(D_{m p}\right)$ for the MPD ISM-II sample pair used in this study. 
IABLE B.3. Determined Values for $D_{m p}$ for MPD Specimen Pairs

\begin{tabular}{|c|c|c|c|c|c|c|c|c|c|c|c|}
\hline \multirow[b]{2}{*}{ ISM } & \multicolumn{2}{|c|}{$\mathrm{DUO}_{2}$} & \multicolumn{2}{|c|}{$\mathrm{Zr}$} & \multicolumn{2}{|c|}{$\begin{array}{c}\text { Average Gap } \\
\text { Between Asperities }\end{array}$} & \multicolumn{3}{|c|}{ Average Mean-Plane Gap } & \multirow[b]{2}{*}{$\%$} & \multirow[b]{2}{*}{$\psi^{(\mathrm{d})}$} \\
\hline & $\#$ & $\gamma_{1}(\mu \mathrm{m})$ & $\#$ & $\frac{r}{r_{2}(\mu \mathrm{m})}$ & $D_{a}(\mu m)^{(a)}$ & $\begin{array}{l}\text { perities } \\
{ }^{\mathrm{Da}}(\mu \mathrm{m})\end{array}$ & $D_{m p}(\mu m)^{(c)}$ & $(\mu \mathrm{m})$ & $\sigma_{m p}$ & & \\
\hline II & 40 & 1.8 & 25 & 1.4 & $2.7^{(b)}$ & 3.3 & 5.9 & & 3.3 & & 1.69 \\
\hline II & 40 & 1.8 & 25 & 1.4 & 18.1 & 4.1 & 2.1. 3 & & 4.1 & & 0.47 \\
\hline
\end{tabular}

(b) Light contact.

(a) $D_{a}=\left[\sum_{i=1}^{19}\left(D_{a}\right)_{i}\right] \times 1 / 10$

(c) $D_{m p}=\frac{1}{19}\left[\sum_{i=1}^{19}\left(D_{a}\right)_{i}\right]+\gamma_{1}+\gamma_{2}=D_{a}+\gamma_{1}+\gamma_{2}$

(d) $\psi=\frac{5\left(C L A_{1}+C L A_{2}\right)}{D_{m p}}$ 


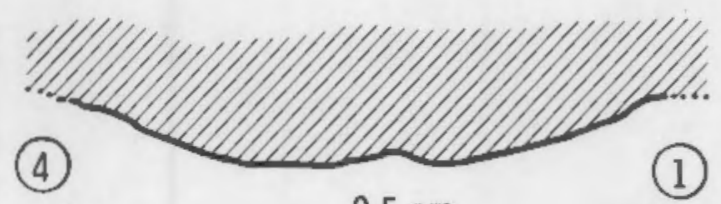

$\mathrm{DUO}_{2}$

(1)
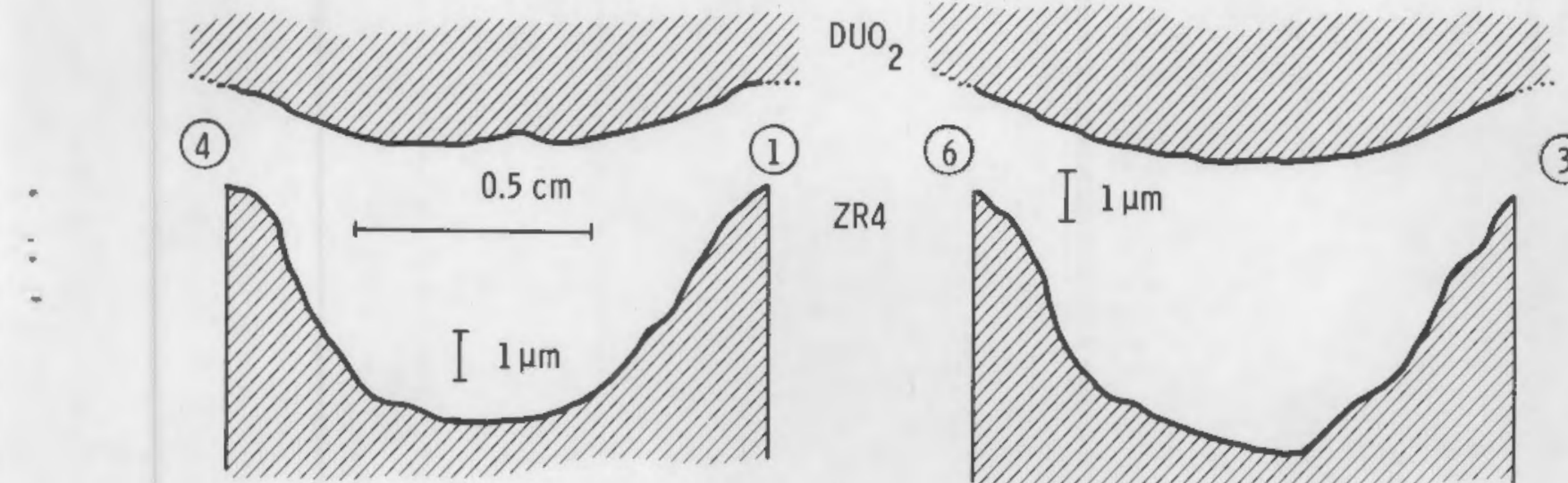

ZR4

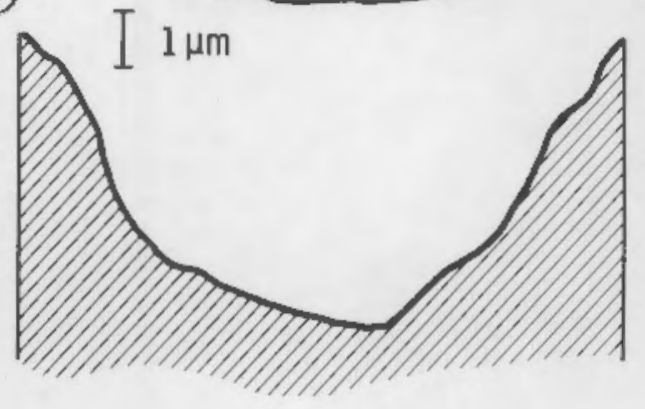

(3)
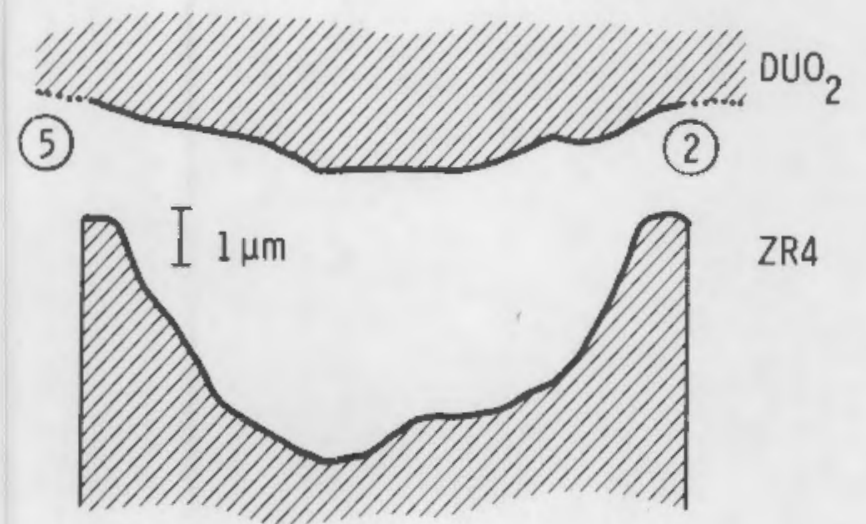

FIGURE B.3. Error of Form for the ISM-II U02-40:2r4-25 MPD Specimen Pair. (Sections correspond to those indicated in Figure F.1.) 



\section{DISTRIBUTION}

No. of

Copies

OFFSITE
A. A. Churm
DOE Patent Division
9800 South Cass Avenue
Argonne, IL 60439

375 Water Reactor Safety Research

Fuel Behavior Distribution R3

27 DOE Technical Information Center

\section{ONSITE}

DOE Richland Operations Office

H. E. Ransom

25 Pacific Northwest Laboratory

D. D. Lanning (2)

R. E. Williford

S. Begej (5)

J. E. Garnier (5)

C. R. Mohr

J. L. Bates

T. D. Chikalla

C. R. Hann

W. J. Bailey

Publishing Cordination (2)

Technical Infomation (5) 



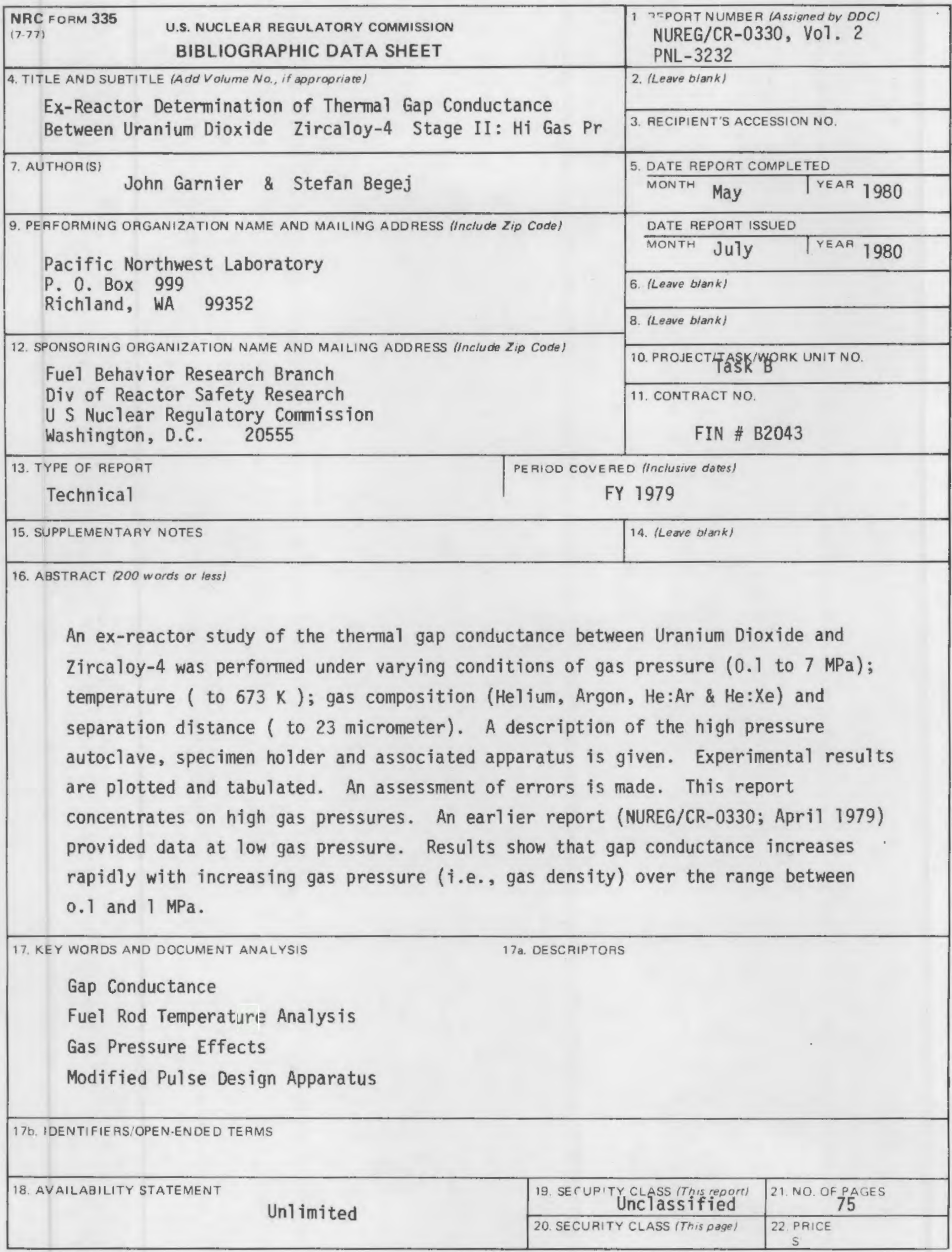




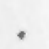

. 